Etnográfica

Revista do Centro em Rede de Investigação em

Antropologia

vol. $12(2) \mid 2008$

Vol. 12 (2)

\title{
Relato etnográfico de un encuentro real: visita al Khuta mafwe, región de Caprivi, Estado de Namibia
}

Ethnographic narration of a royal meeting: a visit to the Mafwe Khuta, Caprivi region, Namibian State

\section{Ester Massó Guijarro}

\section{CpenEdition}

Journals

Edición electrónica

URL: https://journals.openedition.org/etnografica/1815

DOI: 10.4000/etnografica.1815

ISSN: 2182-2891

\section{Editor}

Centro em Rede de Investigação em Antropologia

Edición impresa

Fecha de publicación: 1 noviembre 2008

Paginación: 525-561

ISSN: 0873-6561

\section{Referencia electrónica}

Ester Massó Guijarro, «Relato etnográfico de un encuentro real: visita al Khuta mafwe, región de Caprivi, Estado de Namibia», Etnográfica [En línea], vol. 12 (2) | 2008, Publicado el 05 julio 2012, consultado el 11 febrero 2022. URL: http://journals.openedition.org/etnografica/1815 ; DOI: https:// doi.org/10.4000/etnografica.1815

\section{(c) (7) (8)}

Etnográfica is licensed under a Creative Commons Attribution-NonCommercial 4.0 International License. 


\title{
Relato etnográfico de un encuentro real: visita al Khuta mafwe, región de Caprivi, Estado de Namibia
}

\section{Ester Massó Guijarro}

\begin{abstract}
Se presenta en el artículo una narración etnográfica clásica a través de la descripción densa, en la que la autora pretende abundar, a través de la inevitable subjetividad de la experiencia de campo - y sirviéndose de ella como riqueza mayor frente a una imposible neutralidad -, en los pormenores antropológicos de una visita a un Khuta - autoridad tradicional - mafwe en la región capriviana de Namibia, fronteriza con Zambia, Zimbabwe, Botswana y Angola. La narración etnográfica es empleada como pretexto para ilustrar algunas de las claves de comprensión fundamentales sobre las relaciones actuales entre las autoridades tradicionales mafwe autóctonas y el gobierno namibio, a raíz del intento de secesión armada en agosto de 1999 que produjo el exilio político del anterior jefe mafwe, partidario de la escisión, frente al actual, connivente con el gobierno. A través de la subjetividad etnográfica se pretende una aproximación ajustada, humana y compleja a una realidad social densa, cúmulo a su vez de subjetividades varias, contingencias históricas e ineludibles arbitrios vitales.

PALABRAS-CLAVE: narración etnográfica, Caprivi (Namibia), descripción densa, autoridad tradicional mafwe, secesión armada.
\end{abstract}

1. OBERTURA: EL CAMINO QUE ME LLEVÓ A CHINCHIMANI. AVENTURÁNDONOS EN CAPRIVI

"Lo único que yo deseaba era caminar por una tierra sin mapas."

(Ondaatje 1995: 187)

Las razones que me llevaron a hallarme el día 21 de julio de 2007 en el recinto real del Khuta mafwe, de nombre Chinchimani, región de Caprivi, Estado afroaustral de Namibia, hay que buscarlas en el tiempo unos pocos años antes. Esta experiencia de campo ha de enmarcarse en el contexto de mi investigación 
doctoral para la tesis que tengo previsto presentar a fines del año próximo en la Universidad de Granada para acceder al grado de doctora.

Antes, sin embargo, anticipemos por qué pueda interesar al lector o lectora la mencionada visita. La persona que tuve el privilegio de conocer personalmente encarna uno de los personajes más importantes de la región, más simbólicamente - y pragmáticamente - poderosos. Es un rey (figura 1): uno de los más antiguos, tradicionales y seculares reyes de la región, previos incluso al tiempo colonial.

El trato con un personaje de este calibre no es cuestión baladí; bien al contrario, se halla envuelto en un marcado y antiguo ritual, cuyos pasos resulta inadmisible no seguir, además de en una atmósfera (casi pesadamente) mística: esta persona es considerada cuasi-sacra en el contexto que tratamos.

La posibilidad de una entrevista personal con este rey y su

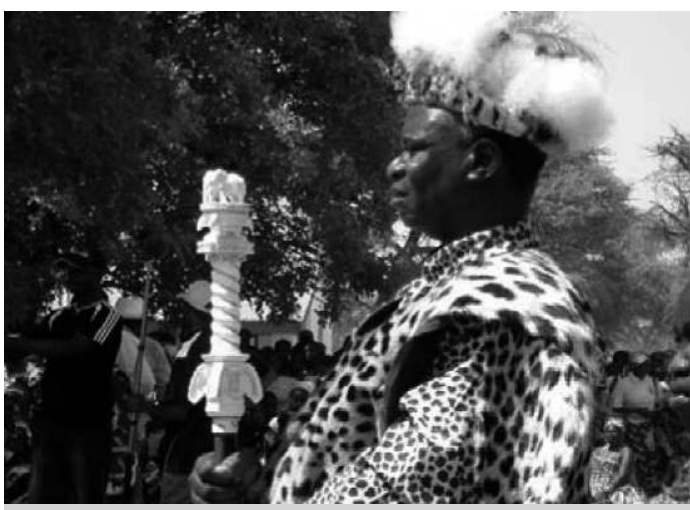

Figura 1 - Fotografía actual del contemporáneo rey Mamili (septiembre de 2006). (Fotografía: autora) consejo (el Khuta), siendo además una mujer (para quien las posibilidades de acercamiento y trato con el monarca se hallan si cabe, siendo foránea, aún más restringidas), significa no sólo uno de los sueños más preciados para cualquier antropóloga sino también, en el marco de la investigación en curso, una experiencia especialmente significativa y oportuna, como tratará de explicitarse en las páginas siguientes.

Se pretende analizar en este proyecto doctoral, desde una perspectiva antropológica, cómo se desarrollan las relaciones contemporáneas entre los ciudadanos de la región de Caprivi (una de las trece namibias), especialmente los pertenecientes a las etnias mafwe y masubia, con el gobierno central namibio, en un plano más concreto, y con la idea de nacionalidad namibia, en un plano más abstracto. Dicho de modo muy sencillo, me interesa conocer cómo se articula lo nacional con lo regional-local-étnico en el contexto de trabajo - con los diversos rostros y variables que asume la vivencia de lo regional y lo étnico, en cada caso; los distintos énfasis, las apreciaciones dispares. Para ello, se planteó dos estancias de trabajo de campo: la primera, de tres meses, en 2006, entre Windhoek (la capital nacional) y Katima Mulilo (la capital regional capriviana); la segunda, de cuatro meses, en 2007, también entre Windhoek y Katima Mulilo (la mayor parte del tiempo en esta segunda localidad).

Mi tarea en el campo consistió principalmente en realizar entrevistas semiestructuradas en profundidad a una muestra intencional con diversos interlocutores 
(según metodología antropológica de corte clásico, con grabadora, transcripción posterior y análisis a la luz de la teoría fundamentada y el análisis del discurso), la observación participante (con su implicación de inmersión cultural, mantenimiento de conversaciones abiertas y espontáneas, etc.) y, finalmente, el acceso a fuentes de información de segunda mano (libros, periódicos, informes, fotografías, etc.) en bibliotecas y archivos diversos del país.

En este contexto, nos hallamos con multitud de particularidades que convierten la situación actual en Caprivi en una bien peculiar, original y difícilmente equiparable a otras situaciones aparentemente análogas (otros contextos de independentismos negroafricanos, en el ámbito internacional, y el resto de regiones namibias, en el ámbito nacional del Estado que nos ocupa): Caprivi es la región más recóndita y alejada de la capital del Estado namibio, cuya capital regional, Katima Mulilo, está situada a 1200 kilómetros de Windhoek, la capital nacional. Tanto a sus efectos históricos como culturales, lingüísticos, administrativos, Caprivi no ha sido parte de la actual Namibia (antigua África del Suroeste) hasta, prácticamente, el momento de la independencia namibia (cfr. Fosse 1996, por ejemplo), ocupada por Sudáfrica hasta 1989 (y uniéndoles en el pasado casi únicamente la lucha anticolonial, a través de las diversas formaciones combativas).

Caprivi (figura 2) se halla situada en una peculiar situación que podría decirse pluri fronteriza (con Angola, Zimbabwe, Zambia y Botswana) y, como es fácil aventurar, las conexiones y relaciones históricas, culturales y étnicas de los habitantes del este de Caprivi (el oeste apenas está poblado por seres humanos: es un parque natural que cuenta con abundante fauna) se hallan mucho más próximas especialmente a Zambia y a Botswana. La zona de la que hablamos fue durante siglos parte del gran imperio lozi, al sur de Zambia (Caplan 1971); y, de hecho, hoy en día el silozi constituye la lingua

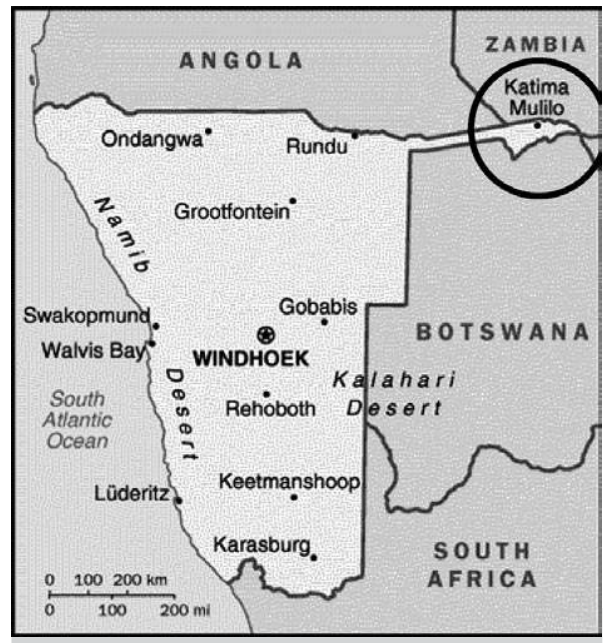

Figura 2 - Región de Caprivi. (Fuente: luventicus.org) franca de la región namibia, gozando el estatus de lengua cooficial con el inglés; lengua, por tanto, de aprendizaje en las escuelas, lengua de la administración, lengua de la academia, siempre en pie de igualdad con el inglés. No es, por cierto, el silozi, lengua materna de los habitantes caprivianos (apenas de pequeños grupos que, por diversas razones biográficas, han estado relacionados en mayor medida con los lozi la sur de Zambia), sino, repito, lingua franca, lengua de paso y de comunicación, 
esperanto de este lugar en el corazón de África, entre los ríos Chobe, Zambezi y Kwando, grandes arterias del continente negro.

En el año 1999 estalla un intento de secesión armada (Fisch 1999a y 1999b) en Katima Mulilo, liderada desde el exilio por sus dos principales artífices: Albert Mishake Muyongo (figura 3), de sangre real mafwe y político profesional (UDP, United Democratic Party, en el seno de la alianza DTA, Democratic Turnhalle Alliance, un partido colonial hasta 1989 y, desde entonces, asociado mayormente a los intereses de los mafwe, ya que fueron éstos durante la colonia los que gozaron del mayor favor por parte de los colonos bóer sudafricanos) y el antiguo rey mafwe, Boniface Mamili, una semi representación de dios en la tierra para este grupo cultural (se irá aportando cierta complejidad a estas nociones, ahora presentadas acaso con cierto reduccionismo en aras de la brevedad introductoria).

El grupo étnico, por tanto, mayormente asociado a la secesión y a las ideas independentistas es el mafwe, frente al masubia que, en este contexto, parece solazarse de su inocencia. ${ }^{1}$ Sin embargo, ni estuvieron todos los que eran, ni eran todos los que estaban; dicho de otro modo, no todos los independentistas son mafwe ni todos los mafwe son independentistas, como he podido comprobar en mi investigación. La asociación popular, no obstante, continúa en escena y con bastante fuerza, por cierto, ya que, como se quejan varios de mis interlocutores del área mafwe, simplemente comunicar cuál es su lengua a la hora de buscar un trabajo, por ejemplo, en otra región de Namibia, ya es motivo suficiente para la desconfianza del posible empleador.

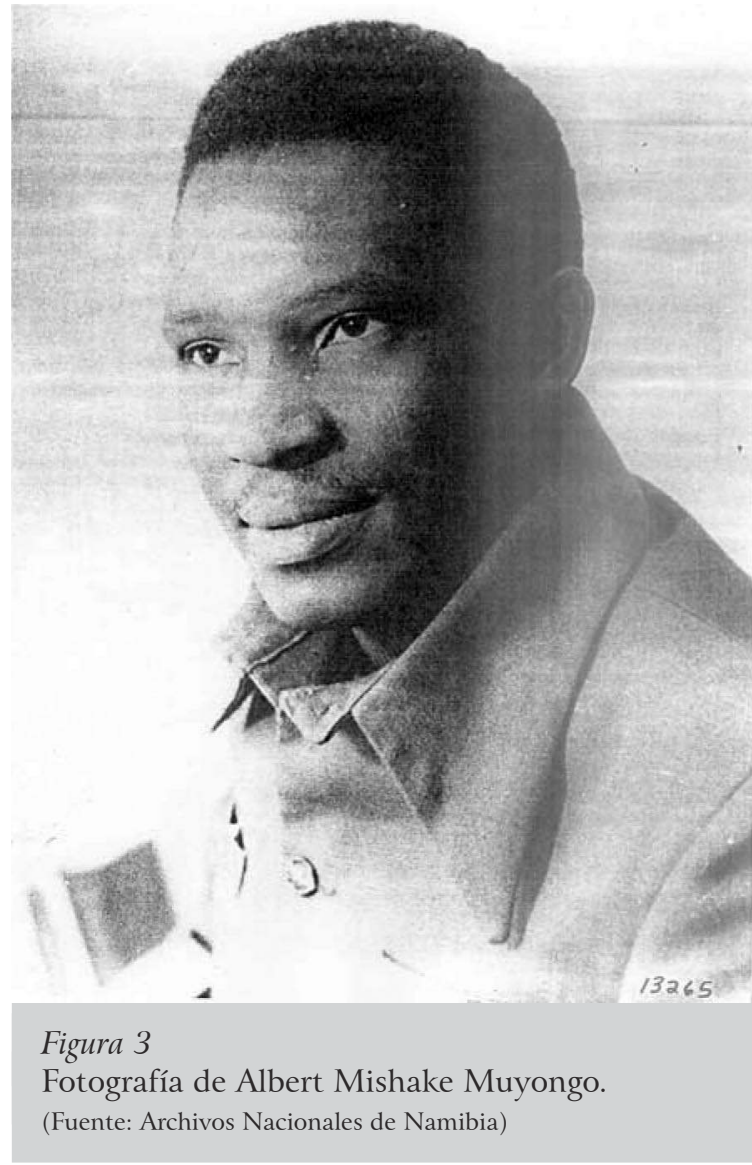

1 Muchos de los testimonios recogidos en las 27 entrevistas en profundidad realizadas dan fe de este dato. 
El intento de secesión, pobremente armado (dicen que gracias a la colaboración de la UNITA angoleña) (Fisch 1999a) y peor organizado, fue abortado (por cierto, con bastante violencia) por el ejército y la policía namibios a las pocas horas de su comienzo, y ello desató todo un debate, de gran calado para el panorama político namibio actual, en torno a la legitimidad de cuestionar las fronteras comúnmente asumidas tras la independencia (también por los hoy instigadores secesionistas: la firma de Muyongo, quien participó en todo el proceso de gestación de la Constitución namibia, se halla en el texto constitucional de 1989, y él mismo se presentó a las dos primeras elecciones generales aspirando a la presidencia del país), de un lado, y, de otro, en torno a la discutible salvaguarda a los derechos humanos que practica el Estado namibio en el proceso, que ya dura casi diez años, de juicio por traición a la nación tanto a los rebeldes secesionistas como a muchas otras personas dudosamente implicadas en la cuestión y arrestadas sumariamente en un primer momento (véase por ejemplo Amnistía Internacional 2006 o Ya Nangoloh 2006).

No es momento ni espacio éste para abundar en estas complejas situaciones que convierten hoy Namibia, a mi entender, en uno de tantos casos fascinantes para el analista de África austral. He querido, sin embargo, tratar de esbozar con trazos mínimos el paisaje que caracteriza hoy este lugar, Caprivi, en su contexto nacional, Namibia, para que más adelante, y según avanza mi narración, puedan ser comprendidos algunos de los hitos cruciales de lo que sucedió aquel $2 \mathrm{l}$ de julio en la corte real mafwe, por qué fue importante para mí como antropóloga acudir a presentar mis respetos a este rey, y otros muchos por qué que irán emergiendo a lo largo de las páginas siguientes.

\section{GESTIONES PREVIAS Y PREPARATIVOS:}

\section{ALLANANDO EL CAMINO HACIA EL KHUTA}

Todo trabajo de campo implica una visión previa, una querencia, un sueño. Y, tras ellos, una ingente sucesión de prolegómenos, obstáculos y desafíos de diversa índole, que pueden abarcar desde lo psicológico hasta lo administrativo, y que el neófito habrá de, entre dosis de paciencia y osadía, enfrentar ineludiblemente.

Ya desde mi primera estancia en el campo (2006) consideré de gran interés antropológico para esta investigación realizar visitas a diversos Khutas. "Khuta" es el nombre en silozi para la institución, el grupo de nobles compuesto por el rey, Litunga², su "primer ministro", Ngambela, su "tercero", Natamoyo (la persona

2 El título de Litunga se asigna solamente al rey mafwe (el equivalente en subia es Munitenge) en el área de Caprivi, siendo originalmente la designación real en silozi para el monarca lozi en la provincia oeste de Zambia. En la actualidad, pues, dos personas ostentan el título de Litunga, aunque técnicamente ello sea irregular (comunicación personal de Bennett Kangumu el 23 de julio de 2007 en Katima Mulilo). 
más próxima al rey, sin embargo, su primer consejero; se cuenta que, en audiencias públicas, puede el rey en ocasiones prescindir de la compañía de su Ngambela, pero nunca de su Natamoyo), y sus indunas, jefes consejeros diseminados por las diferentes localidades de la región. Estas visitas podrían resultar interesantes no tanto para abundar en los temas centrales de mi trabajo (para los que eran las voces populares y "consuetudinarias" las que más contaban), cuanto para aprovechar la oportunidad de conocer cómo son las formas contemporáneas en Caprivi de acceder a un rey y abordarle formalmente - material antropológico de primera mano de invaluable interés.

Así, como digo, ya en 2006 y desde la Universidad de Namibia, gracias a un profesor mafwe capriviano que comenzó a enseñarme algo de silozi, preparamos juntos unas cartas de presentación de acceso al Khuta (figura 4), firmadas tanto por mí como por el jefe del Departamento de Sociología (Volker Winterfeldt, el profesor al que he de agradecer la invitación a la Universidad de Namibia), con sellos y membretes varios, redactadas en un lenguaje muy respetuoso, casi pomposo.

Aquello fue el primer paso. Hasta el año 2007, durante mi segunda estancia de campo, no pude hacer uso de aquellas cartas de presentación. Como puede leerse en ellas, lo que parece pretenderse por su contenido es la obtención del permiso del Khuta para realizar investigación en las áreas de su competencia (o, dicho de otro modo, en las áreas de las que el Khuta es dueño, las que le pertenecen, a saber, la tierra comunitaria). Sin embargo, y teniendo en cuenta que comencé a realizar entrevistas en 2006, tanto en Windhoek como en Katima, ${ }^{3}$ a diferentes personas mafwe y masubia sin haber pedido ningún permiso previo (el hecho de no trabajar en áreas rurales y tierra comunal, que son las que principalmente "pertenecen" a los diferentes Khutas, me exime en parte de aquella responsabilidad), plantea las cosas de otra manera: es evidente que yo, como investigadora occidental, no considero que deba pedir permiso a nadie para favorecer que la gente ejerza su derecho a la libertad de expresión; mi interés de visitar el Khuta y conocer al rey era de índole antropológico pero, dada mi situación, hubo de "hacer pasar" las cosas por un cierto filtro honorable que implicaba, a su vez, aquella extraña petición de permiso. Veremos más adelante cómo se ejecutó la delicada cuestión.

Mas, ¿por qué era tan importante conocer al Khuta? Mejor aún, ¿por qué el Khuta es tan importante en sí?

3 Mi trabajo se desarrolla principalmente en áreas urbanas; no he acudido a zonas rurales a hacer entrevistas ya que, por limitaciones de tiempo, he tenido que circunscribir mi muestra en buena medida a personas habitantes de área urbana (y teniendo en cuenta, sin embargo, que la distinción urbanorural en el contexto que nos ocupa es bien diferente de la que podría realizarse en Europa; posee muchos matices particulares y, aunque no es éste momento de ocuparnos de ello, téngase en cuenta que su línea divisoria ha sido ya ampliamente debatida y discutida por relevantes estudiosos africanistas contemporáneos) (Mamdani 1996). 

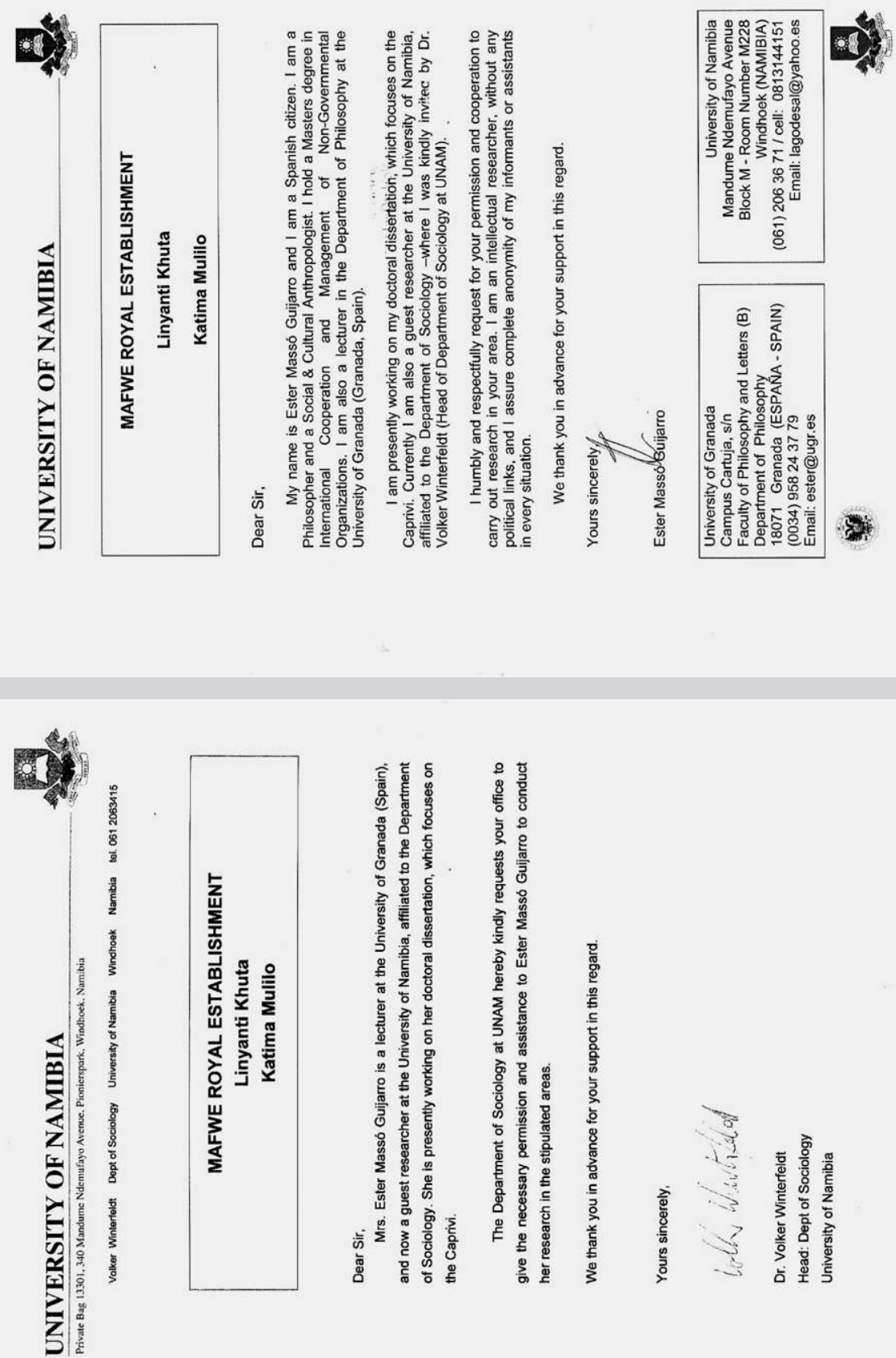

\section{Figura 4}

Cartas de presentación al Khuta (Volker Winterfeldt y Ester Massó Guijarro). 
En África, la cuestión de la autoridad tradicional ha devenido central en los estudios de los últimos tiempos (Winterfeldt 2002). Mientras que durante la euforia de las primeras independencias africanas se quiso desdeñar la customary law (llamémosle "ley consuetudinaria") y, especialmente, sus ejecutores, las autoridades tradicionales, porque se los asociaba con la era colonial, ${ }^{4}$ hoy en día, en plena resaca de aquella alegría - comprensible pero a veces ciega,$-{ }^{5}$ no ha habido más remedio que volver la cabeza a aquellas instituciones seculares de las autoridades tradicionales, instrumentalizadas, bien es cierto, a menudo por las administraciones coloniales; empleadas, sí, a menudo como el mango que ostentaban los colonizadores para hurgar en y controlar a los diferentes pueblos, según la proverbial indirect rule. Pero, con todo ello, también representantes de un pasado africano que bulle aún hoy, viva imagen de una forma de autoridad, de legitimidad, de asociación, intrínsecamente distinta de la importada por la colonia y que, mal que pudiera pesar en la borrachera panafricanista de los años sesenta, no sólo ha pervivido hasta hoy sino que los gobiernos africanos han tenido que rendirse a la turgente evidencia de que, sin su apoyo, sin la colaboración de las autoridades tradicionales, sencillamente el Estado en África no llegaría a muchos de sus rincones (cfr. Hinz 2005).

Hoy, en el moderno Estado de Namibia, las diversas autoridades tradicionales de los numerosos grupos étnicos no sólo son "toleradas" sino incluso fomentadas por el Estado: reciben un sueldo del mismo, tienen derecho a jubilarse en un momento dado y todo lo que les concierne está regulado según leyes específicas, las "Traditional Authorities Act" (Namibian Government 1999). No constituyen, pues, de ningún modo, una realidad marginal o invisibilizada sino todo lo contrario: palmarias y tangibles instituciones de enorme poder, movilizadoras de grandes cantidades de recursos (económicos, humanos) y cuya función política resulta crucial (Hinz 2002) (aunque las asociaciones populares a su concepto no sean con la política y, de hecho, muchos ciudadanos critiquen que las autoridades tradicionales estén tan "politizadas" hoy en día). De hecho, no hay más que atender la notable presencia de diversas personalidades políticas (ministros, a veces incluso el presidente o el primer ministro en su lugar) durante la celebración de los festivales culturales anuales en honor de los diversos reyes.

Así que las autoridades tradicionales, hoy, vuelven a ser tema de debate y de estudio, una proteica realidad incomparablemente africana, no susceptible de explicarse en otros términos que no sean los africanos (y ello, en cada contexto diferente con sus particularidades), no asimilable en ningún caso a las autoridades

4 Fueron claros instrumentos de la metrópoli para ejercer control en las zonas rurales, especialmente; es, de hecho, demasiado fácil instrumentalizar y malignizar en el enfermizo contexto de una colonia (Fanon 1964).

5 Como ya auguraron muchos, recordemos a Dumont (1963) y lo que por aquel entonces parecía un injustificado pesimismo aguafiestas. 
acaso "primitivas" de otros tiempos sino rotundamente actuales, en convivencia diaria con las autoridades estatales y la política institucional y a medio camino, siempre, entre la función del árbitro social - la política al fin - y la significación simbólica de poseer "sangre real", de encarnar el compendio de la sangre de todo el pueblo, de todos los ancestros. En tales figuras se recoge la historia del pueblo, tantas veces no escrita; su valor, sus tradiciones, sus querencias, y también sus invenciones, cómo no (el más antiguo de los festivales que ahora se realizan en honor a los reyes en Caprivi data de... i2002!; bien es cierto que existen noticias de otro tipo de festivales previos a los que hoy se realizan, con su forma contemporánea, pero siempre a través de la instrumentalización colonial) (Kangumu 2006). Porque, al fin y al cabo, qué es si no, cualquier tradición, sino un cuento colectivo siempre reinventado (Hobsbawm y Ranger 1996).

Explicado, pues, el enorme interés de conocer al Litunga mafwe, recordemos que ya en 2006 habíamos preparado cartas de presentación, desde la Universidad y con ayuda de dos profesores (uno capriviano, el otro namibio-alemán). El presente año 2007, al regreso a Caprivi a inicios del mes de julio (Sikulu, en silozi), y aprovechando un viaje del profesor capriviano de la UNAM a Katima Mulilo, realicé un encuentro con él durante el que volvimos a tratar el tema de la visita al Khuta. En el mismo bar donde nos encontramos, esta persona realizó una llamada telefónica a un pastor adventista (por razones de respeto al anonimato, evitaré citar nombres propios a lo largo de todo este texto), buen amigo suyo y al parecer una persona muy próxima al Khuta mafwe, que habría de ser mi segundo contacto hacia él. En efecto, confirmó, el pastor estaría dispuesto a ayudarme; anoté su número de móvil y al día siguiente lo telefoné por la mañana.

A las doce en punto del medio día me encaminé hacia su despacho (en una cooperativa agrícola de la zona, sita en la capital) donde recién me había citado, y lo hice acompañada de dos personas: una, mi pareja, cuya presencia adquirirá una relevancia de interés antropológico fundamental (y que será comentada más adelante); otra, un buen amigo capriviano masubia (y téngase en cuenta que el pastor a quien íbamos a ver era mafwe), activo miembro local tanto en el ámbito político como asociativo y que, especialmente durante mi segunda estancia en el campo, devino un interlocutor-puente fundamental (proporcionándome sustanciosos contactos, sobre todo con miembros de diversos partidos políticos, incluso en la clandestinidad).

Gracias a esta persona, el encuentro con el pastor mafwe ${ }^{6}$ fue acaso más sencillo de lo que podría haber sido, dadas las circunstancias que iré describiendo.

6 Este señor, el pastor, mantenía una actitud a medio camino entre la "simpatía política" y la displicencia; se me antojaba uno de esas personas fundamentalmente autoritarias, acostumbradas a mandar, con una sonrisa, sí, pero a mandar; incluso, tan poco habituadas a escuchar opiniones que [continua] 
Durante la entrevista con él, salpicada de interrupciones varias durante las que se ausentaba (parecía un hombre muy ocupado, y desde luego parecía también gustarle mostrarse así), le hice entrega de las cartas de presentación y le expuse los motivos de mi interés, ayudada por mi acompañante masubia. Él me escuchaba, entre sonriente y displicente, y me hizo a su vez varias preguntas, insistiendo mucho, constantemente, en que el Litunga - el rey es una persona muy ocupada, con muchas obligaciones y mucha gente que quiere visitarle. También realizó una crítica a los investigadores, you researchers, empezó diciendo, soléis reducirlo todo, simplificarlo todo siempre mucho, y después continuó con una crítica bastante fuerte a la idea de la inviolabilidad de las fronteras coloniales tras las independencias. Esperó mi opinión (o mi respuesta) ante ello, y yo asentí enfáticamente a la crítica del reduccionismo; concuerdo plenamente en que el reduccionismo exotizante ha sido el cáncer de los estudios africanistas durante mucho tiempo, precedido por el cáncer del reduccionismo racista colonial; en la actualidad, pienso, sin embargo, que existen numerosas tendencias de estudios africanistas rigurosos, no tan susceptibles ya de aquella crítica. Aduje, empero, que la decisión de romper el statu quo en torno a las fronteras africanas habría de proceder de África y sólo de África, nunca de Europa (en la que él parecía declinar esta responsabilidad); habría de constituir, por tanto, un (difícil y largo, seguramente) trabajo de negociación y consenso por parte de los propios gobiernos africanos.

Parecía aguardar mi respuesta, como si yo tuviera tal alquímica y secular solución en mis manos...

Finalmente, la impresión debió de ser mínimamente favorable (además de que contábamos con la "venia" previa del profesor capriviano de la UNAM, respetado miembro de la comunidad mafwe), porque nos comunicó que al día siguiente (itan pronto!), en que ellos tenían previsto un viaje, podríamos acompañarles y que "ya veríamos" si había alguna posibilidad de que el Khuta nos recibiera. Todo ello, entre mucha pompa y circunstancia, circunloquio y rodeo, casi confusión incluso. Era evidente que aquella aura de especialidad y exclusividad había de rodear al Khuta en todo momento...

Y todo ello, sin embargo, no fue óbice para que nos preguntara si teníamos un coche para desplazarnos; no lo teníamos, mientras que él, en cambio,

[continuação] disientan de la suya propia que, ante ellas, ni siquiera parecen ser capaces de escucharlas; es como si les "resbalaran", de modo inconsciente en una involuntaria sordera transitoria. Seres sin capacidad para la diferencia. Era evidente que ostentaba poder, incluso tal vez carisma.

Tal vez parezcan al amable lector o lectora estas consideraciones excesivamente subjetivas, pero tengo por principio que el trabajo de campo antropológico posee mucho, de forma irremisible, de subjetivo, y que en ello reside también gran parte de su valor. La neutralidad no existe; sí lo hace, sin embargo, la honestidad intelectual, y tratar de practicarla es lo que me lleva a intentar, también, la descripción objetiva de los sucesos, sin perjuicio de poder realizar puntuales observaciones - inevitablemente - subjetivas. 
cuenta con uno para sus frecuentísimos viajes, vehículo que, sin embargo, no ofreció. Era como si toda esa pompa, toda esa superioridad, no estuviera en absoluto reñida con ponerle las cosas difíciles al blanco-mokua ${ }^{7}$-rico que pretende conocer al jefe, aunque ese "ponerle las cosas difíciles" pase por un casi abuso de la situación (nosotros no teníamos coche; él sí, y además iba a realizar ese viaje de cualquier modo, según dijo, aunque más tarde quedará claro que el único motivo del viaje éramos nosotros). Adujimos que intentaríamos alquilar un coche, y así quedó la cosa, hasta el día siguiente a las dos de la tarde, un sábado, un Lapelekelo, en silozi.

Acudimos junto a nuestro amigo-puente subia a preguntar por los alquileres de coches en una empresa turística local. Eran aberrantemente altos, precios para turistas (norte) europeos ricos, auténticos mokua, y no precisamente para el bolsillo flaco de una investigadora latina no doctora. Así que, ante nuestro desánimo, nuestro amigo se ofreció a volver a llamar por teléfono al pastor, explicando la situación. Finalmente se llegó a la solución de cortesía de que ellos, los mafwe, pondrían el coche (el coche que siempre les llevaba, de hecho), pero pagando nosotros la gasolina.

Es decir, que su importancia, su pompa, su reluctancia a la hora de presentar la visita al rey como algo de gran complejidad y proceso, no estaban reñidas con la posibilidad de "sacarnos el dinero", aunque es obvio que los Khutas manejan muchísimos recursos - también dinero líquido, por supuesto. ${ }^{8}$

Los pasos "trampilla” hacia el Khuta habían sido dados. Alea jacta est. Ahora, sólo restaba intentar descansar algo esa noche antes, intentar acallar esos nervios silenciosos ante el evento increíble que íbamos a presenciar.

Sólo una curiosidad antropológica más antes de continuar. Aquella noche recibí un mensaje en mi teléfono móvil namibio, enviado por el profesor capriviano de la UNAM que me había proporcionado el contacto con el pastor adventista (y con quien yo no había vuelto a hablar), pidiéndome que, por favor, "dejara” en Katima a mi amigo-puente subia que nos había acompañado en todo el proceso (please leave K. tomorrow).

¿Qué significaba eso? Todo eso significaba los siguiente: punto uno, el pastor mafwe le había contado que el subia había estado presente durante la entrevista; punto dos, llegaron a pensar que esta persona pudiera tener algún interés en "apuntarse" al viaje sin ser invitado, cosa que por cierto no sucedió, dados el conocimiento y la prudencia de este señor (y dejando a un lado que,

7 Término local en silozi para designar, con cierto velado despecho, al blanco-rico. Ambas nociones parecen ir unidas en el intraducible "mokua" - desde luego, poco ajustado para una investigadora novel española: no somos tan blancas pero, especialmente, no somos tan ricas.

8 No realizo ningún juicio sobre esto; sencillamente lo menciono como aspecto interesante de valores, usos y costumbres culturales tan diferentes de los nuestros de origen como europeos occidentales. Reconocer lo emic desde lo etic, para no dejar nunca de fascinarnos con lo diferente, aunque podamos hacerlo, momentáneamente, nuestro. 
como persona de otra etnia y hombre, además, nada gustoso de las "tribalizaciones", no tenía lo que se dice ningún interés personal en visitar el Khuta mafwe); punto tres, el pastor adventista le pide al profesor que sea él quien me advierta que debo "dejar" a este señor subia, es decir, no permitir que viniera al viaje, en lugar de hacerlo él mismo.

Es obvio que la apariencia de buenas relaciones que pude observar entre el pastor y mi amigo-puente durante nuestro encuentro era sólo, en efecto, eso simplemente: apariencia. $\mathrm{O}$, dicho de un modo pedestre (bendito sea lo pedestre), en todas partes cuecen habas.

Pero continuemos con nuestro periplo...

\section{RUTA HACIA LINYANTI}

Habíamos quedado, pues, con el pastor adventista que nos llevaría al Khuta mafwe, a 65 kilómetros al sur y al oeste de Katima Mulilo, a las dos de la tarde en la puerta de su oficina de aquel arenoso y caluroso sábado, Lapelekelo de julio, Sikulu (si bien julio en Namibia es invierno, las condiciones geográficas tropicales de Caprivi hacen que ni siquiera entonces haga demasiado frío).

Se retrasó casi media hora y, finalmente, nos recogió en uno de esos coches que abundan allá, que sólo cuenta con asientos en la parte delantera y cuya parte trasera, muy grande, es como un gran maletero sin ningún tipo de asientos, donde todas las vibraciones del vehículo retumban en todos los huesos del cuerpo, en caso de ser personas lo que porte. Nosotros, por supuesto, en continuación con su actitud displicente, algo superior y poco amable, iríamos detrás (él conducía y le acompañaba otro hombre que, más tarde, se reveló como el intérprete, además de una persona mucho más próxima, emocionalmente hablando, que el pastor) ${ }^{9}$

El camino consistió en un primer tramo breve de carretera asfaltada y una mayor parte sin asfaltar. Íbamos dejando un reguero de polvo que no permitía ver lo que quedaba atrás. Los numerosos poblados, mínimas casitas circulares de adobe con techo pajizo, se ubicaban al lado izquierdo de la senda porque allí es donde queda el lago Liambezi, una de las grandes reservas de agua de la región.

Gente caminando por ambos lados del camino, que saludaban al pasar. Las eternas mujeres vestidas de mil colores con los eternos cestos en sus cabezas

9 Antes de comenzar el viaje hicimos un alto en la gasolinera, donde el pastor nos pidió el dinero sin ninguna contemplación antes de llenar el depósito; la cantidad que nos pidió (four hundred will be enough) superaba en unos cien dólares namibios lo que le costó llenar el depósito (que, por supuesto, no llegaría ni a dejar a la mitad en los poco más de cien kilómetros que duraría la travesía). Era evidente que todo formada parte de un "espontáneo" plan destinado a dejar claro quien mandaba allí. En la gasolinera muchas personas nos miraban, sorprendidos de que fueran los dos mokua los que iban en la parte trasera del coche, en lugar de los dos negros delante. Algunos de ellos incluso sonreían divertidos. Cosas del apartheid. 
y los eternos bebés en sus espaldas, en su andar pausado, casi lánguido pero constante. Hombres, niños, ancianos, casas, ganado. Alguna vez hubimos de parar, porque un grupo de vacas había decidido aposentarse en el camino para una oportuna siesta.

Y el perenne paisaje africano, el bush, los arbustos ahora secos porque la estación lluviosa quedaba lejos; los inmensos árboles recortados contra el cielo, las serenas acacias de copas planas, los generosos baobabs centenarios; el olor a liana, a tierra seca, a madera viva; las señales de tráfico viejas, raídas, advirtiendo de los elefantes.

África, en su persistencia tranquila, pacífica, silente.

Por fin, tras un rato largo en aquella parte trasera traqueteante, donde el ruido de la vibración del coche entraba hasta el fondo de los oídos y las posaderas hacían de "almohada" para todos los huesos del cuerpo, fuimos llegando a la morada real mafwe...

\section{LLEGADA, ENTORNO Y ESPERA RITUAL}

Al principio parecía un poblado más de los tantos que habíamos ido dejando atrás, con casas levantadas junto a empalizadas de troncos, adobe, bosta de vaca, arbustos trenzados. Pero, a poco que el coche avanzaba hacia dentro, y alejándose del camino, resultaba sencillo constatar lo específico del lugar. Lo más llamativo, tal vez, la enorme antena de repetición de móviles. Una muestra tangible, directa, enhiesta, casi abrupta, del poder del lugar donde nos hallábamos, de los recursos que la gente que lo habita es capaz de movilizar y utilizar (figura 5).

Algunas casas de construcción, todas de piso bajo, y una empalizaba más alta y mejor elaborada de lo normal (tan espesa que realmente no se podía ver el interior), seguían indicando que donde nos hallábamos no se trataba de un poblado cualquiera. Uno de los edificios en concreto (figura 6) presentaba los dibujos de unos animales simbólicos del Khuta mafwe, y pintado en grandes letras negras el nombre de la casa real.

Por fin, paramos el coche. Bajamos (saltamos, mejor dicho, del maletero), deseosos de estirar las piernas, y el

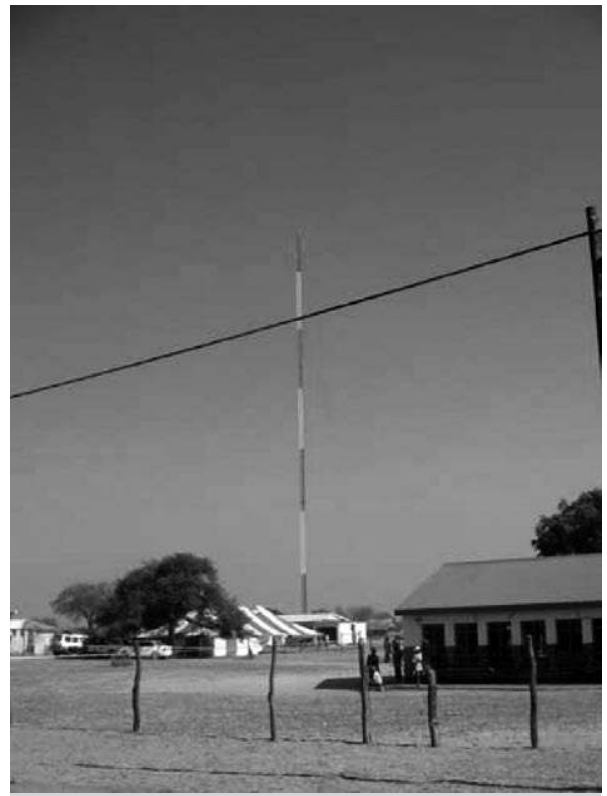

Figura 5 - Fotografía del emplaziamento real mafwe (septiembre de 2006). (Fotografía: autora) 
pastor nos pide que esperemos allí - con el intérprete - mientras él va a hablar con el rey. A estas alturas del asunto, lo cierto es que nosotros todavía no teníamos muy claro si podríamos ver al rey aquel día o no, ya que la mañana anterior nos habían explicado que estaría muy ocupado (como siempre), que tendría que recibir a muchas personas ilus-

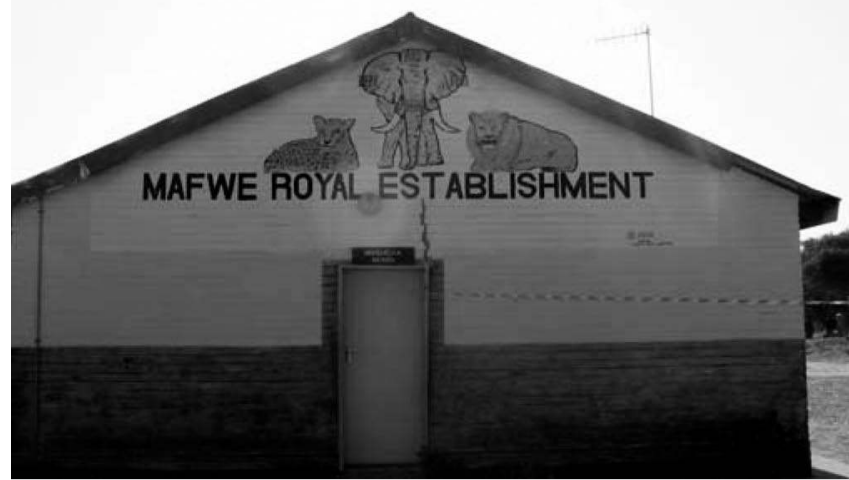

Figura 6 - Fotografía de la caza real mafwe (septiembre de 2006). (Fotografía: autora) tres, que había varias audiencias pendientes y no sé cuántas cosas más; tal vez, nos dijo el pastor, no podría recibirnos y asistiríamos simplemente para citarnos otro día; o tal vez podríamos sólo saludarlo, presentarle los respetos, y marcharnos.

El juego con la incertidumbre (a través de lo que podríamos llamar la espera "ritual") resultaba crucial para generar esa atmósfera de respeto y temor, ese ámbito incluso de lo misterioso, pero el caso es que, palabrejas aparte, nosotros seguíamos sin saber qué se cocería allí, qué sucedería, o cuán de vano, o no, habría sido nuestro africano peregrinaje.

Mientras aguardábamos al sol, fuera de la gran empalizada, el intérprete me hizo algunas preguntas con su amable sonrisa perenne. Cuando le "confesé" que me interesaban ciertas cuestiones políticas, inquirió, sin perder la sonrisa, si eso no me parecía demasiado "delicado", sensitive. Me indigné. Claro que lo es, de hecho; estamos hablando de Caprivi, estamos hablando de un lugar donde hubo un intento de secesión armada muy conflictivo hace menos de diez años que aún colea en varias formas, que aún crea dolores y por el que ha demasiada mucha gente ( siempre es demasiada); estamos hablando de muchas otras cosas que se irán desentrañando poco a poco. Claro que es delicado. Pero me indigné de pronto ante una pregunta tan abierta y directa, llegados a ese punto, porque mi metodología consiste en hablar con gente, en preguntarle a la gente, en recoger sus particulares y diferentes voces (y, a menudo, las menos llamativas, las más marginales), y por tanto, si la gente está dispuesta a contarme cosas (y lo está, de facto), ¿quién es nadie para preguntarme si no estoy abordando un tema demasiado delicado?

Me indigné internamente, claro pero, por supuesto, respondí mesurada y comedidamente. Lo que me esperaba dentro explicará muchas de estas cosas, 
y verá el paciente lector que aquella pregunta del intérprete sería casi la más inocente e ingenua de las que hube de responder allá adentro...

Antes de que el pastor regresara para confirmarnos que, en efecto, sí, el rey podía recibirnos, llegó para saludarnos otra persona, un anciano con una gorra de plato y pobremente vestido, aparentemente un sirviente. Después se reveló, sin embargo, como uno de los miembros del Khuta, presente durante todo el encuentro junto al resto de consejeros. Este anciano señor nos saludó en silozi y charló brevemente con el intérprete en la misma lengua. Acaso no supiera inglés; eso siempre quedará como un misterio, de interesantes implicaciones, por cierto, como se irá viendo si quieren seguir leyendo...

\section{LA ENTRADA Y EL RECIBIMIENTO}

Así que podemos entrar, por fin. Me sentí nerviosa, sin saber qué esperar, sin referencias, aunque traté de mantener la compostura y fingir que todo seguía funcionando bien. Forma parte de este trabajo: al fin y al cabo, no se deja de representar un rol, de cumplir un papel, a veces casi teatral dependiendo del momento, y en aquel entorno, en aquel ámbito, una no podía ser precisamente "una misma”...

Cruzamos la empalizada, por fin, y allí nos reunimos con dos hombres más, todos sencillamente vestidos, incluso pobremente; uno de ellos con un mono de trabajo verde. Nos acercamos a una construcción de obra de planta baja y, antes de aproximarnos a la puerta, nos arrodillamos y comenzamos a batir palmas, en tres tandas. Nosotros, por supuesto, imitábamos constantemente los diversos gestos de protocolo (previamente nos habían aleccionado en ello, pero resultaba un poco confuso el orden de los diversos gestos explicado de modo teórico; finalmente, la imitación fue, como suele suceder, la vía más efectiva).

Aunque nos habían advertido que, por ser extranjeros (y por tanto no súbditos del rey), se nos permitirían ciertas licencias, no se nos ocurrió ni de lejos dejar de hincar la rodilla en el suelo, con la mirada baja durante todo el proceso y las manos respetuosamente posadas en el regado, entrelazadas, ya preparadas para la siguiente tanda de palmadas (punto final que corrobora el respeto ritual que ha de acompañar a cualquier comentario o acto).

Como mencioné anteriormente, mi compañero me acompañó al evento que describo. Esto va a requerir de comentarios aparte más adelante (puesto que la relevancia de ciertos asuntos de género se revela grande), pero diré ya que su presencia no resultaba en absoluto neutra o baladí en lo relativo a mi recibimiento y mi aceptación (o no) en aquel Khuta. La cultura profundamente patriarcal del lugar donde nos hallamos hace que una mujer que se mueve sola (si bien en caso de ser extranjera se pueda, en buena medida, suspender el juicio en torno a ello) no sea a menudo bien vista, y menos en círculos y ámbitos tan tradicionales como el que nos hallábamos. El hecho de que me acompañara mi pareja, pues, incluso la posibilidad de presentar la situación como si él hubiera venido a 
"salvaguardar" y "defender" mi bienestar y hasta mi honra (aunque ello sea del todo punto inexacto, o mejor dicho falaz, y por supuesto innecesario para mí como persona, como investigadora y como mujer, aparte de personalmente irritante, como cualquier mujer de mi entorno habitual comprenderá), facilitaba bastante las cosas. Además, la cultura y la tradición aquí no comprenden una mujer sin un varón al lado - mal que me pese.

Y fue así, tal cual, como se presentó la situación en su momento: un respetable matrimonio donde el hombre cumple su sagrado deber de protección del lado débil, alias yo, que, sin embargo, soy en este caso la que se mueve, la que investiga, la que viene. Pero digamos que la apariencia que pudimos ofrecer en aquel contexto y en aquel momento tuvo, de tal guisa, más visos de verosimilitud y respetabilidad que en el caso de haber acudido yo sola (aunque huelgue decir, o tal vez no, que por supuesto podría haberlo hecho y, estoy segura, el resultado tampoco habría sido catastrófico; finalmente la presencia de mi compañero fue circunstancial y contingente, no necesaria, como revela también el hecho de mi experiencia en el campo, completamente a solas, del año anterior 2006; sirva esto como aliento a compañeras investigadoras y antropólogas).

Nos arrodillamos, pues, y proferimos otras tres tandas de palmadas. Entramos en la habitación. Yo no levanté la vista en ningún momento; como mujer, no se me está permitido ni siquiera mirar al rey a la cara y, aunque no pude evitar echar una ojeada rápida en algún momento (fingiendo ingenua timidez), lo cierto es que no puedo contar demasiado con mis recuerdos "visuales" a este respecto porque, por protocolo, el hecho es que sólo debía mirar mi falda. Vestido, por cierto, que tenía guardado desde el año pasado, y que usé entonces (el 24 de septiembre, Mwimunene, de 2006) para asistir al festival cultural, Lusata, en honor del rey mafwe que ahora tenía frente a mí; vestido, pues, realizado con la tela de rigor para honrar al rey: blaquiazul, y con la inexpresiva cara del monarca mismo estampada en varios lugares (figura 7). Así que, durante toda la audiencia, puede decirse que tuve mis manos encima del rostro real (es decir, en la tela de mi regazo). El hombre, en cambio, no tiene por qué ataviarse de ninguna forma especial para presentarse al rey.

Al entrar en la habitación (no excesivamente grande, de unos veinte metros cuadrados, con dos ventanas), siguió una tríada más de palmadas, rodilla en el suelo. Y, por fin, en medio de grandes silencio y solemnidad, tomamos asiento.

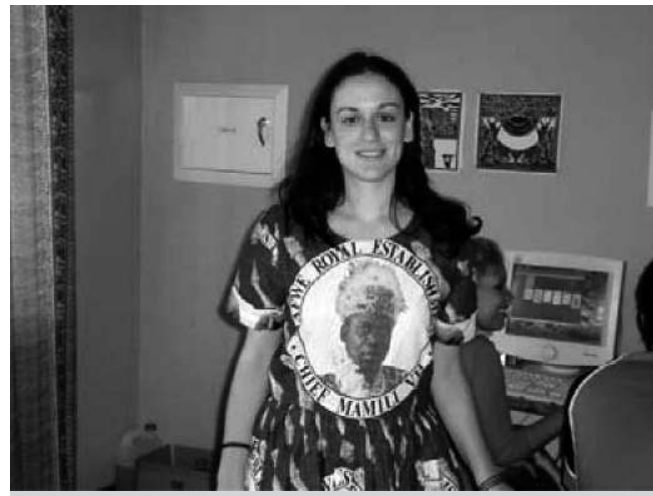

Figura 7 - Fotografía de la autora vestiendo la indumentaria mafwe (septiembre de 2006). (Fotografía: Damir González) 
Hay sólo cinco sillas, aparte de la del rey, irregulares entre sí. Algunos de los consejeros (cuatro en total, a excepción del Ngambela; algunos entran más tarde) se sientan en el suelo. Apenas miro brevemente al rey, sentado en una silla grande frente a una mesa como de oficina, llena de papeles agrupados en diversos montones, y con una máquina de escribir encima. En la sala, decididamente humilde y sucia (con insectos muertos y vivos en el suelo) al menos según parámetros occidentales, había colgados algunos pósters de SWAPO (el partido en el gobierno) a modo de decoración, como para dejar las cosas claras (se explicará en su momento el por qué de la insistencia en mostrar esta adhesión, esta lealtad, de modo explícito).

El rey vestía una camisa y unos pantalones veraniegos, de andar por la calle. Con gafas de sol, sandalias llenas de polvo (eso sí lo pude ver bien, porque en lugar de la cara le miraba los pies), semblante imperturbable, hierático, casi adusto, sentado muy erguido y solemne. A lo largo de toda la audiencia su gesto más activo fue el de espantar moscas constantemente con un objeto alargado que tenía sobre la mesa, una especie de pequeño cetro ritual.

En una silla situada a la diestra del rey, el Ngambela, humildemente vestido, casi andrajoso, calzando unas chanclas de playa con unos calcetines completamente destrozados y polvorientos. Es mayor, más anciano que el rey (maduro, mas no anciano), con mirada profunda y una corta barba bastante canosa.

Nosotros, sentados en sillas frente al rey, a una distancia generosa: el pastor, el intérprete, mi pareja y yo. Aguardando. No he sentido tal misteriosa expectación antes en toda mi vida, en aquella sala sencilla, casi humilde, llena de moscas acaloradas, rodeada de aquellos hombres sucios de polvo y mal vestidos, que no dejaban de mirarme y que emanaban, empero, una dignidad y un señorío difícilmente igualables.

Mi encuentro con el Khuta había comenzado...

\section{TRANSCURSO DE LA VISITA Y CONTENIDOS FUNDAMENTALES. DESCRIPCIÓN DENSA ${ }^{10}$}

\subsection{Silozi: la lengua ritual}

Por fin, comenzaron a hablar. Hablaban en silozi, que en aquel contexto del Khuta posee la indudable función de lengua ritual, aunque tal vez no sólo.

10 Nota previa: He de aclarar que el empleo de grabadora o cámara fotográfica durante el encuentro fue del todo punto imposible; de hecho, impensable desde el principio, dadas las características de la cita. Lo que se narra a continuación constituye una reconstrucción memorística de la autora, pergeñada el mismo día del encuentro, tras éste, y con la ayuda de la memoria de la otra persona presente, su compañero, José Ángel Martínez Casares, a quien le agradezco profundamente su colaboración como "recordante". Lamento no poder complementar esta descripción densa con fotografías del lugar o algún otro tipo de información audiovisual. La amable lectora o lector habrán de confiar, si lo tienen a bien, en mi palabra. 
Me explico. El inglés, aunque probablemente conocido por todos ellos (acaso tal vez por absolutamente todos; acaso los más ancianos no lo sepan hablar y esa sola razón ya bastaría para que la lengua fundamental de comunicación fuera el silozi), ${ }^{11}$ no es su lengua; no es la lengua de allí, la lengua de la tierra, la que se puebla de significados emocionales y en la que se sueña el destino colectivo. No tendría sentido celebrar una sesión del consejo, una sesión del Khuta, en inglés, en la "lengua del imperio". ${ }^{12}$

Así que, pese a que lo más probable es que todos los presentes fuéramos perfectamente capaces de entendernos en inglés, la sesión se celebró en su totalidad en silozi, con traducción simultánea del intérprete al inglés. En un momento dado de la audiencia sonó el teléfono móvil del rey (que, dicho sea de paso, se hallaba encima de la mesa, pitando y parpadeando sin ningún pudor) y, cuando éste contestó (acto que, por cierto, pareció no resultar inconveniente a sus ojos en medio de toda aquella solemnidad formal), habló en inglés.

Había que aguardar a que hablaran los grandes hombres, los hombres del consejo. Y, mientras yo mantenía mi cabeza - siempre - baja, el pastor y el intérprete, por turnos, hablaban dirigiéndose no al rey, ya que nadie está autorizado hablar directamente con él (ni siquiera ellos), sino al Ngambela, su primer ministro, su mano derecha, en efecto sentado a la diestra del egregio monarca con sandalias.

Le hablaban en voz muy baja, sumamente respetuosa, casi temerosa. En silozi. El Ngambela escuchaba, como primer intermediario.

I I El Khuta mafwe posee bajo su ala varios grupos etnolingüísticos, no solamente el mafwe (matotela, mbukushu, etc.), y podría parecer lógico que su lengua ritual de comunicación fuera propiamente el sifwe. ¿Por qué, sin embargo, emplean el silozi? Ello se debe a las razones históricas por las que la zona ahora mafwe fue durante siglos ocupada por el imperio lozi; aún hoy en día, el Khuta mafwe considera que su verdadera raíz se halla en Barotseland, en la provincia más al sur de Zambia. También por ello escogieron el nombre de Litunga, como se comenta, para su rey: el mismo título que ostenta el rey en la zona lozi de Zambia. Complejas situaciones, algunas de cuyas implicaciones cruciales veremos en el último epígrafe.

12 Empleo esta expresión en un sentido figurado, más centrado en la actualidad ya que, de hecho, la lengua "del imperio", es decir de la opresión, de la colonización, en Namibia tanto como en Sudáfrica fue el afrikáans; la lengua del apartheid, de Botha, de Smuts, fue el afrikáans; la lengua en la que se castigaba a Mandela y a tantos otros, y la que el mismo Madiba quiso aprender durante sus 27 años de presidio para conocer mejor el sistema que le mantenía encerrado y que oprimía el espíritu y la sangre de su hermoso pueblo.

Cuando en 1989 Namibia es declarada independiente, el inglés se proclama como lengua oficial en sustitución del afrikáans (por cierto, no conocido por la mayoría, aunque sí especialmente "escogido" como lengua de comunicación entre los "coloureds", mezclados, lo que es buena muestra de ese deseo de "parecerse a" la parte dominante, esa extraña reacción de cuasi autohumillación que Fanon describió mejor que nadie). El inglés, así, hoy, opera casi como lingua franca general, nacional, y es hablado por todo el mundo y estudiado en todas las escuelas namibias. 


\subsection{Ngambela: el primer intermediario}

Ya hemos descrito al Ngambela más arriba, su atuendo humilde y casi andrajoso que contrastaba con su porte digno, su mirada profunda entre las arrugas antiguas de su rostro. Tras escuchar lo que el pastor y el intérprete le comunicaban - en silozi -, se dirigió al rey, él sí; cuando llegó a su altura, se arrodilló a su lado derecho, casi en actitud de plegaria, batió palmas de nuevo y, finalmente, sentándose en el suelo a la derecha del monarca (como metáfora física de lo que representa en esta particular "coreografía de poder"), ${ }^{13}$ también en baja voz, le habló de nuevo en silozi - presumiblemente contándole, repitiéndole, lo que acaban de comentar los dos primeros.

El rey no habla, no todavía; sólo escucha. El Ngambela regresa a su asiento, vuelve a hablar dirigiéndose solamente al pastor y al intérprete. Entonces, y sólo entonces, el intérprete se dirige hacia mí.

\subsection{El intérprete, segundo intermediario}

Bajando mucho la voz, volviendo la mirada hacia mí, en una actitud ya no sólo de respeto sino casi de recato, el intérprete me preguntó a qué había ido, por qué me encontraba allí. Tragando saliva, expliqué en inglés lo mejor que pude, igualmente en voz baja, comedida, y apenas mirando solamente al intérprete, que, como investigadora interesada en trabajar en el área, consideraba adecuado acudir a presentar mis respetos al Khuta y pedirle permiso para ello, para "moverme" por sus lugares.

Expliqué, además, que ésa era mi segunda vez allí, mi segunda estancia de campo. Como comprobé en breve, aquello fue un error, un exceso de información que no jugó precisamente en mi favor (por suerte, tampoco acabó por estropear las cosas).

Cuando terminé mi breve y nerviosa perorata - aunque intenté mantener el tipo -, prosiguió mi esposo, aún más breve, explicando el motivo de su presencia como acompañante protector. Todos asentían complacidos, como pude observar por el rabillo del ojo. Qué feminista felicidad.

Cuando terminamos ambos, el intérprete, siempre muy solícito y sonriente en su recato, asintió y, volviendo el rostro hacia el Ngambela, explicó en baja voz y de nuevo en silozi lo que habíamos contado - o eso parecía. Después, el Ngambela lo comunicó al rey (quien, por cierto, es de imaginar que lo hubiera comprendido todo desde nuestra primera exposición en inglés). Los circunloquios ayudaban, indudablemente, a prestar pompa y circunstancia a la audiencia, a aumentar la sensación de honorabilidad y distancia insalvable entre el Litunga y los mortales.

A esas alturas yo todavía continuaba un poco nerviosa, mientras los pequeños bichos - los vivos, ya que también había difuntos - correteaban por el 
suelo no demasiado limpio de la corte donde nos hallábamos, los indunas continuaban guardando un silencio sepulcral, y el rostro del rey, en lo que pude apenas entrever, y a pesar del espantamoscas improvisado y el móvil (objetos ellos presuntamente triviales, capaces de ayudar a relativizar el momento e, incluso, dotarle de cierta comicidad, aunque reír allí habría sido, supongo, un "suicidio" rápido), continuaba de una seriedad mortal.

\subsection{El Litunga, dueño de los mafwe}

El rey, el Litunga Simasiku Mamili, apenas habló a lo largo de todo el evento; ni siquiera hablaba cuando el Ngambela se dirigía directamente a él para comentarle algo; asentía, espantaba moscas, y continuaba con su seriedad mortal, su hieratismo impertérrito. Supongo que su sola presencia era motivo de todo; su sola presencia confería a aquel encuentro polvoriento la suficiente aura de divinidad como para convertirlo en algo trascendente. Y era eso, exactamente, lo que sentíamos en aquellos momentos.

A esta altura puede comentarse la curiosa anécdota, tal vez paradójica, de que durante mi estancia de campo del año pasado pude realizar en Katima Mulilo una entrevista con nada más y nada menos que una de las hijas del rey, VM, por aquel tiempo trabajando en el ciber local más popular. VM, de 22 años, me concedió una entrevista mientras comíamos un suculento almuerzo en un bar, sin ningún tipo de pompa ni protocolo. Llevaba casi un año entero con la voz de la hija de aquel solemne personaje, a quien ahora no podía mirar a los ojos, almacenada cuidadosamente en mi grabadora digital. Supongo que, en su momento, su padre no fue consciente de este encuentro pero, como se explicará más adelante, es muy probable que, de haberse conocido este hecho, podría haber sido considerado como una falta de respeto, casi sacrilegio, acaso por la simple y llana razón de que no se pidiera permiso previamente a él, a su padre y, más que eso, su rey.

Probablemente él ignorara también que, pocos días después de este encuentro, entrevisté en su lugar de trabajo (la biblioteca del Caprivi College of Education, en Katima Mulilo) a una de sus dos esposas, una de las Muoli (reina), precisamente la madre de VM, quien habló sin tapujos ni solemnidades sobre todo lo que apeteció (o eso parecía, dentro de ciertos límites).

La información más interesante que esto nos ofrece es, a mi entender, el hecho de que, pese al gran peso de la autoridad que parece emanar del Litunga, las personas bajo su jurisdicción, las que le respetan, incluidas las más cercanas, no dejan de disfrutar de cierta libertad individual cuando les acomoda, sin necesidad de pedir un permiso previo a "su señor" para conceder una entrevista a una humilde investigadora española... incluso sobre temas tan sensitive como el de la secesión armada de 1999! 


\subsection{Preguntas y control: la censura del Khuta, el miedo del Khuta}

Después de la transmisión directa del Ngambela al rey, aquél volvió a sentarse en su lugar y, seguidamente, habló largamente en silozi dirigiéndose principalmente al intérprete. Al fin, éste me explicó: no era comprensible que hubiera empezado ya mi trabajo (desde 2006; parece que sí fue, pues, un error mencionar que aquella era mi segunda estancia) sin antes, como primer paso, pedir permiso para ello al dueño del lugar; no era comprensible que una persona llegue a un sitio que no es el suyo y comience a recorrerlo sin pedir permiso previo al "dueño del cortijo", del "cortyard", dijeron. Todo esto me lo comunicaba entre sonriente y prudente, como reconviniéndome casi con dulzura - como a una niña pequeña que ha hecho algo malo sin saberlo, por ignorancia, aunque en aquel contexto la cosa no dejaba de atemorizar bastante -, mientras yo asentía con cara de póquer, sin dar crédito aún del todo que aquellos señores se creyeran con el derecho de pretender limitar en lo más mínimo mis pasos, los míos, ciudadana de otro lugar, en efecto, y asistida por mi "derecho humano" de libre movimiento, entre otros. Pero, naturalmente, estos sentimientos míos eran los más esperables en primera instancia para una persona criada en la retórica de los derechos humanos y la autodeterminación personal, imbuida de las ideas feministas más recalcitrantes y autocomplacientes (lo digo orgullosa) y antropóloga social, para más señas. Es decir, un espécimen femenino perfectamente representativo de la cultura académica de norte, endoculturada y socializada en el discurso (a menudo quedando sólo en eso) de corte más liberal de nuestras sociedades occidentales complejas.

A pesar de todo eso que no era comprensible, continuó diciendo el intérprete ofreciendo un giro conciliador al asunto, bueno, más vale tarde que nunca y, finalmente, habían decidido apoyarme y valorar que estuviera allí - aunque fuera tarde. Es mejor hacer las cosas así, puntualizaba: con permiso y a la luz, porque eso significaba que podría moverme libremente y sin miedo. Ello parecía plantear las cosas de modo que pareciera que yo, antes de acudir al Khuta, habría estado investigando poco menos que a hurtadillas y a escondidas, lo cual es rotundamente falso porque, sencillamente, ni siquiera había podido imaginar que, para ejercer su derecho de libre expresión concediéndome una entrevista, las personas mafwes - o lo que fueran - con las que hasta entonces había conversado hubieran tenido que pedir permiso a nadie, ni siquiera a su rey. Pero, por supuesto, mi visión no tenía por qué coincidir con la del Khuta, y estaba claro quién mandaba aquí.

Por el discurso del intérprete, entre reconviniendo y conciliando, como digo, parecía además desprenderse una cierta confusión en la comprensión de los términos: mi trabajo se desarrolló principalmente en el área urbana de Katima Mulilo - área no étnicamente "designada" como mafwe o como masubia, mayeyi o mayuni -, mientras que aquel señor apelaba constantemente al hecho de "moverme" por los pueblos, evidentemente los pueblos del área mafwe. 
Aquí los pueblos son agrupaciones pequeñas de casitas de adobe y paja, sin luz ni agua corriente la mayoría; es lo que, en nuestra jerga, llamaríamos más bien "poblados". Por su parte, lo que he denominado "área urbana", Katima Mulilo, capital de provincia, constituiría un pueblo pequeñísimo en Europa.

El caso es que yo no había estado investigando en los pueblos; por motivos varios circunscribí mi investigación en Katima, como ya he comentado. Así que parecía haber una cierta confusión en la insistencia del intérprete en la expresión "cuando vayas a los pueblos". Tras estos comentarios, reitera que me otorgan su "venia" y, es más - aquí llega lo más interesante -, me ofrecen su colaboración directa para el trabajo: que, si lo necesito, me acompañe siempre una persona mafwe, designada por ellos, que puede ser el profesor de la UNAM en las ocasiones en las que él viaje de Windhoek a Katima.

Esto que suena tan bonito esconde una serpiente dormida en su regazo, como se fue revelando poco a poco junto al miedo, el urgente deseo de control: temen - explican - que pueda hablar con las personas equivocadas porque, dentro de los mafwe, hay muchas divisiones y tal vez haya quien me mienta, quien no me cuente la historia tal y como sucedió (otra confusión: piensan que mi investigación es sobre la historia del lugar). Así que mejor que me acompañe siempre alguien.

Me da la oportunidad de hablar y yo me apresuro a tratar de aclarar, previo agradecimiento a sus concesiones (es superior a mis fuerzas pedir disculpas por el supuesto agravio de no haber acudido antes), que no tengo intención de moverme por los pueblos, al menos no por motivos de mi investigación, sino que deseo centrar mi trabajo en Katima, como vengo haciendo desde 2006.

Se repite el ritual de la transmisión: yo hablo en inglés, dirigiéndome al intérprete; él lo repite en silozi para el Ngambela (deseo incidir, llegados a este punto, que el elemento de las palmadas se sigue repitiendo a cada instante: cada vez que cualquiera de los presentes termina de hablar, él mismo y todos los demás damos una serie de varias palmadas, como para corroborar y refrendar que respetamos el discurso, como una especie de extraña muestra sonora de aceptación y bienvenida). El Ngambela le habla a él (el rey de momento apenas ha pronunciado palabra) y, sólo entonces, el intérprete vuelve a preguntarme en inglés con quién tengo intención de hablar, y con qué personas he hablado hasta la fecha. La sucesión de preguntas que siguen no tienen desperdicio, y trataré de reconstruirlas lo más fielmente posible:

- cuál es mi interés;

- si tengo intención de hablar con otras personas - no mafwes, tal vez -, aparte de ellos;

- con quién he hablado hasta ahora;

- si ya he comenzado mi trabajo y dónde. 
Resumiendo, una perfecta invasión que tal vez yo misma he favorecido por emplear los términos de "ir a pedir permiso al Khuta" y no simplemente los de "vengo a presentar mis respetos".

Difíciles respuestas. Por supuesto, era impensable traicionar la confianza y la colaboración de mis numerosos interlocutores e interlocutoras previos al encuentro dando la más mínima información sobre sus nombres. Al final, solución de cortesía: uno, mi interés era hablar con personas diferentes, acaso, sí, con diferentes visiones, porque eso es lo que aporta riqueza a una investigación, y a eso no puedo renunciar (la libertad de acción y movimientos y expresión es el cáliz sagrado de cualquier investigador, pienso, aunque eso por supuesto no lo digo allí); dos, hasta ahora prácticamente lo único que he hecho ha sido hablar con gente. Punto. Ah sí, y volver a agradecer la ayuda, a la que recurriré con certeza en caso de necesitarla; insistir en que trataré de ser lo más honesta y rigurosa posible con mi investigación, de hacerla lo mejor de lo que fuera capaz (aquí no miento, ni siquiera piadosamente), y que tantas y tantas gracias por aquella audiencia estupendísima.

$\mathrm{Al}$ final el intérprete explica que ellos no pretenden decirme lo que tengo que hacer, sino ayudarme en lo que necesite. A caballo entre la protección y la censura o, tal vez más claramente, intento de censura disfrazada de protección y consejo. Ahora la pregunta inicial del intérprete, antes de entrar, de sobre si tratar de política no sería demasiado "delicado", cobraba todo su significado.

\subsection{Los consejeros: el resto de miembros del Khuta}

Tras mi pequeño discurso, pronunciado lentamente para tratar de mejorar la (dudosa) calidad de mi inglés oral, y en voz baja, mirando a los ojos al intérprete y adoptando una actitud respetuosa, con la cabeza baja y las manos sobre el regazo (y previa transmisión en silozi de mis palabras al Ngambela), interviene uno de los indunas, sentado a mi lado en el suelo. Habla durante un pequeño rato, en silozi, dirigiéndose directamente al Ngambela. Después, el intérprete me traduce: el profesor de la Universidad (pronuncia su apellido, precedido por la partícula "bo", signo de respeto en silozi) apenas está ahora en Katima; vive en Windhoek y sólo viene puntualmente a Caprivi, así que durante sus ausencias voy a necesitar otro "guía" (censor) en caso de necesitarlo. Parece que ese guía, por consenso, se decide que pueda ser el mismo intérprete, cosa que me alegra sobremanera porque parece un hombre dialogante, de mirada franca y nada altiva; no impositivo sino buscador del consejo. $\mathrm{O}$ al menos eso parece.

Siempre y cuando necesite tal guía, por supuesto, insiste el intérprete. Tiempo para que yo hable: vuelvo a agradecer su generosa ayuda. El hecho de que me "asignen" como ayudante en primer lugar al profesor de la Universidad constituye un gran alivio para mí ya que esta persona es un intelectual, un librepensador que, ya desde el año pasado, cooperó conmigo hasta el punto de devenir el primero de mis interlocutores para una entrevista en profundidad 
- la primera, de hecho, que realicé. Así que es de presumir que cuento con su ayuda para, sencillamente, poder seguir trabajando sin ningún tipo de interferencias, y aunque la versión oficial para salvar la cara ante el Khuta sea que bo "profesor de la Universidad" (insisto en respetar el anonimato, y a pesar de que él en concreto insistió en que podía usar su nombre siempre) sería mi guía y consejero.

El induna-consejero del Khuta que había realizado esta precisión fue el único que habló durante toda la audiencia; el resto, también sentados en el suelo en diversos lugares, apoyados en la pared, se limitaron a mirar y escuchar, pero tan solo la intervención de aquél (precisamente el que vestía un mono de trabajo verde, un hombre alto y robusto de mediana edad) ya fue una muestra interesante de cómo funciona un consejo Khuta.

El que menos habla es, precisamente, el rey. El Ngambela parece no sólo el transmisor de su voz para los "mortales" sino también, como "primer ministro" y, supongo, gozando una cierta autonomía decisional y de juicio, es quien puede hablar e incluso aportar veredictos, sin necesidad de que el rey se pronuncie. El resto de miembros, los indunas, pueden participar en las deliberaciones dando su opinión, en silozi por supuesto, y dirigiéndose directamente al Ngambela - no al rey, nunca al rey, a quien sólo se dirige su Ngambela.

He de aclarar, por cierto, que la figura del Natamoyo (consejero, generalmente descendiente por línea materna), el "tercero" del rey, no pude observarla durante mi visita. Como, naturalmente, las circunstancias no eran lo que se dice propicias como para ponerse a preguntar motu proprio (la entrevista fue más bien de ellos a mí que de mí a ellos), mi sola observación participante no bastó para poder discernir si alguno de los presentes era el Natamoyo. En caso de haberlo sido, lo cierto es que no se distinguió en nada del resto de indunas, ni en comportamiento, ni en el modo y el lugar de sentarse en el suelo, etc.

Después de la intervención del consejero, y tras la transmisión ritual, el pastor adventista volvió a intervenir, comentando que existía un libro sobre la historia del lugar que me recomendaban encarecidamente, porque ése no "contaba mentiras" como otros, y había muchos libros mentirosos circulando por ahí. En algunos momentos del encuentro yo no lograba dar crédito a lo que oía; era tal el nivel de censura al que me parecía que estaban llegando. Mi compañero, acaso más hábil para ciertos "movimientos diplomáticos", se apresuró a decir que muy gustosos aceptaríamos leer ese libro y considerarlo como fundamental (finalmente ni siquiera anotamos el nombre; nunca me han gustado las recomendaciones bibliográficas que nacen del miedo o la censura).

Esto explica igualmente el hecho de que, justo antes del encuentro, en la puerta de la empalizada real, el pastor adventista me preguntara muy circunspecto si conocía el "pequeño libro de Maria Fisch" (Fisch 1999a). Yo le conté que no sólo lo conocía sino que lo había leído en profundidad el año anterior, y él asintió aún más circunspecto. En un epígrafe futuro, ya en breve, 
explicaremos por fin los motivos para el miedo del Khuta, recogidos también, en parte, en ese polémico librito de la médica alemana afincada en Namibia, señora Fisch, con quien mantuve personalmente en 2006 la extraña conversación telefónica que en más adelante narraré.

\subsection{La presencia de un acompañante masculino: breve apunte sobre el patriarcado}

A lo largo de toda la interesante audiencia, como era comprensible dados nuestros diferentes "roles", mi compañero apenas habló; fundamentalmente, lo hizo al principio y al final, ya que las preguntas iban dirigidas a mí como investigadora "en primera persona" (y acaso contraviniendo la costumbre más arraigada de la mujer como propia del espacio doméstico y el hombre propio del espacio público). Sin embargo, hubo un momento en que la intervención de mi pareja resultó de crucial interés y, creo, de ayuda decisiva para la obtención de la benevolencia de los ojos del Khuta.

Justo al terminar mi "discursito" anteriormente descrito, y antes de que el intérprete pudiera retomar su labor de traducción mirando al Ngambela, mi compañero tomó la palabra, corroborando todo lo que yo había dicho y asegurando, tal vez más enfáticamente que yo, que aquella ayuda nos sería de gran utilidad, y que todo lo que pudieran recomendarnos sería invaluable, etc.; además, añadió - acaso sin venir mucho a cuento, pero resultó de fábula - que él, que el año anterior no había podido acompañarme, había pedido permiso en su trabajo este año para poder venir conmigo, porque no le parecía bien que su mujer se moviera a solas por aquí, ya que no era bueno que una mujer estuviera sin su correspondiente compañía (iescolta?) y... en fin, todo ese tufillo patriarcal que él intuía infaliblemente que sería bien recibido.

Y sí, fue infalible. Yo le miraba, mientras él hablaba, manteniendo la cara de póquer con toda deportividad. Ese que usaba él entonces es un lenguaje desconocido para nosotros en nuestra vida en España, pero allí, entonces, parecía estar gozando de un éxito rotundo, si atendemos a los enfáticos asentimientos de cabeza de todos los hombres presentes que yo atisbaba, de nuevo, por el rabillo del ojo, sin levantar la cabeza de mi falda por supuesto.

Es indudable ahora para mí que aquella intervención, que haría sacar los colores de furia de cualquiera de mis compañeras antropólogas feministas de la Universidad - y con toda razón -, constituyó en aquel momento un gran acierto por parte de mi compañero ya que, y aunque no venía exactamente a cuento a tal altura de conversación, tiñó el contexto de un aura de respetabilidad y dignidad muy congruente con los valores que imbuían el lugar donde nos hallábamos.

El hecho es que esta anécdota "de género", por así llamarla, constituye sólo la punta del iceberg de lo que venía sucediendo días antes, a lo largo de mi experiencia de campo en esta segunda ocasión. Durante mi primera 
estancia, en 2006, viví sola en Katima Mulilo todo el tiempo; este año 2007, sin embargo, mi pareja me ha acompañado y, aunque su compañía no se incluye en los "momentos de trabajo" - por ejemplo durante mis entrevistas, como es de rigor, y salvo excepciones como las de la visita al Khuta -, está resultando de un interés antropológico grande poder contrastar la estancia del año anterior, a solas, con la de éste, como mujer emparejada acompañada de su cónyuge.

Antes de proseguir quisiera, pues, comentar algunas pinceladas sobre estas diferencias en asuntos de "trato de género". El año pasado todas las personas que conocía, al no existir "alternativa" masculina - ni femenina, por ende - junto a mí, me estrechaban la mano como se estrecha aquí para saludar, se dirigían a mí para hablar, me miraban a los ojos, etc. Es decir, se relacionaban conmigo con normalidad, como ente independiente. Este año, cuando nos encontramos con conocidos, o nos presentamos a alguien, la mayoría de personas dan sólo la mano a mi pareja o, en caso de que yo tienda la mía, como mucho la estrechan brevemente y evitando un exceso de contacto visual, como si alargar el apretón pudiera constituir un insulto o una molestia para mi compañero. A veces incluso ni me miran a los ojos (una mirada prolongada a los ojos puede resultar insinuante, en según qué contextos). La última persona a la que miran, antes de despedirse, es a él, y alargan el apretón de manos con él, profundizando la mirada a los ojos con la que lo acompañan, como para reconocerle, mientras que a mí ni siquiera me miran. Aunque sepan que yo soy la investigadora y vengo aquí a trabajar, y que mi compañero está de vacaciones. Todo eso da igual. Los siglos pesan mucho más...

En otros contextos, con otras personas aquí, hemos vivido cómo en el ámbito del hogar se acepta e incluso se fomenta que yo, como mujer, colabore en tareas "de la casa": cocinar, fregar después de comer... incluso aunque estemos invitados, de visita, mientras que a mi pareja se le prohíbe casi que toque un plato, y su gusto por cocinar es dudosamente visto como una excentricidad de los hombres españoles (supongo que es la mejor alternativa que se les ocurre frente a la de la homosexualidad).

El vino tinto, ese delicioso vino afrutado sudafricano que se cultiva en los viñedos de Groot Constanza cerca del Cabo de Buena Esperanza, es sólo para los hombres. A mí, como mujer, se me ofrece como mucho una bebida de apenas cuatro grados de alcohol, parecida a la sidra, con suave sabor a manzana. No vaya a ser que me pierda.

Para un lector o lectora españoles será evidente que las diferencias no son tantas ni demasiadas con respecto a muchos de los rasgos que aún perviven de nuestra ibérica cultura patriarcal. Corramos un tupido velo... 


\subsection{Atuendos: reyes en gafas de sol, primeros ministros en chanclas. Una digresión sobre el concepto de elegancia y respetabilidad}

Como he venido comentando, los atuendos de los miembros del Khuta, incluido el del Litunga y su Ngambela, no eran precisamente lo que, desde la cultura occidental higienista y obsesiva con el protocolo "del aspecto físico", por así decir, cabría esperar.

Las personas "grandes", los "grandes hombres" de la cultura occidental, cuando se hallan en eventos públicos, han de supuestamente cuidar al extremo su apariencia y su indumentaria, no concibiéndose que las ropas estén rotas o sucias, por ejemplo. Igualmente, se asume que ciertos elementos de la vida cotidiana, ciertamente prosaicos o triviales, como un teléfono móvil, han de mantenerse retirados o en suspenso durante un evento ritual importante; dicho de otro modo, el monarca español, por ejemplo, haya probablemente de mantener su teléfono móvil apagado durante una audiencia pública o diplomática.

¿Por qué, cuál es el por qué en general de estas normas sociales y protocolarias de toda cultura? Están destinadas, sin duda, a través de las nociones aceptadas de elegancia, a conferir respetabilidad, ese aura de intangibilidad, de seriedad, de normativa que marca la diferencia entre hechos como ir a comprar el pan y hechos como entrevistarse con un rey. Sin embargo, como en todo, si bien existe la pauta común de que hay una norma establecida, esas normas difieren entre sí en cada contexto.

Es evidente, pues, que el uso de chanclas de la playa, calcetines rotos, gafas de sol o teléfonos móviles durante una audiencia real en el Khuta mafwe no significan allí motivos para romper esas auras, porque sencillamente, si lo fueran, no se practicarían. Es evidente que las nociones de elegancia, que es la transformación estética de la respetabilidad, devienen diferentes en este contexto porque, sencillamente, eso es lo que muestran las conductas y actitudes que pudimos observar en el Khuta mafwe.

El Ngambela era la segunda persona más honorable de la sala, el segundo en el rango, el único autorizado para hablar con el rey. De considerar que el uso de calcetines impolutos fuera importante para remarcarse socialmente aquella relevancia trascendente del personaje, es obvio que éste, el Ngambela, llevaría de hecho calcetines impolutos, y tal vez zapatos cerrados de piel en lugar de chanclas, ya que resulta también de todo punto claro que la razón para no llevar otros calcetines no es la carencia de efectivo: el Khuta maneja en primera instancia los recursos de la comunidad y, como mencioné, la inmensa antena de repetición de móviles situada junto a uno de los depósitos de agua cercanos a la "empalizada sagrada" no indicaba precisamente, en África, pobreza material.

El interés de comentar y remarcar todo esto no es solamente el obvio de relativizar sobre los conceptos de elegancia, divergentes en cada cultura, asociados al de respetabilidad. Hay también una intención de relativización cuasi 
moral en ello: occidente tiene la obligación, el imperativo ético, de reconocer de una vez por todas que hay muchas maneras de hacer las mismas cosas...

\subsection{Venia del Litunga y despedida. Regreso a Katima Mulilo}

Tras el prolongado periplo (el encuentro dura aproximadamente una hora) consistente en preguntas de ida y vuelta, traducciones y palmadas constantes, finalmente habla el rey: en voz no muy alta, casi extrañamente suave, muy serio, mirándome aunque yo apenas puedo mirarle a él, de nuevo. El intérprete me traduce: eres bienvenida, aprueba el trabajo que la "mujer blanca" va a realizar, te desea buena suerte y espera que nuestra ayuda te sirva. Parece que, a fin de cuentas, el más amable de todos ha sido el mismo Litunga. O bien, que todas las críticas y censuras posibles ya las han realizado sus consejeros, que conocen bien su trabajo y han "hecho los deberes"...

A mi vez, agradezco profundamente esas palabras, reitero que presento mis respetos al rey y aseguro que trataré de hacerlo lo mejor posible.

Se cierra la sesión. Nos levantamos y volvemos a hincar la rodilla en el suelo, dando tres tandas de palmadas. Salimos, sin dar nunca la espalda al Litunga y, de nuevo, reconstruyendo o rehaciendo el camino que tomamos al llegar, también en la puerta, ya desde fuera y sobre la tierra, nos arrodillamos. Otra vez, la tríada de palmadas.

Después estrechamos la mano de algunos de los consejeros, que han salido con nosotros (no todos), agradecimientos de nuevo y, sin más dilación, subimos en el coche con el pastor adventista al volante y el intérprete, y regresamos a Katima Mulilo, en el mismo camino de tierra polvorienta, árboles centenarios, poblados diseminados (ahora quedan a mano derecha, cerca del lago Liambezi) y vacas indolentes en medio de la carretera.

A medio camino paramos para recoger a una mujer de mediana edad que se dirige también a Katima, cargada con un gran fardo. Nos saludamos en silozi (mu tozi cuañi? Hande...), sonreímos pero no entablamos conversación.

El viaje de regreso, entre risas tan nerviosas como - ya - aliviadas, transcurre rápidamente.

Aquella hora de nuestras vidas no se borrará fácilmente de nuestras mentes y corazones... Todavía duraba, todavía dura la profunda emoción, la indeleble huella que los acontecimientos tan radicalmente "otros" tallan en el alma humana. 


\section{COLOFÓN. AL DÍA SIGUIENTE: “LO RESPETO, LO TEMO, PERO...”. EL POR QUÉ DEL MIEDO DEL KHUTA}

\footnotetext{
"No pertenecemos a nadie ni somos monógamos en nuestros gustos y experiencias.” (Ondaatje 1995: 187)
}

\subsection{Los "peros" de la gente y los "peros" de la política}

Domingo por la mañana, huerto de Ishubu, comarca rural de Katima Mulilo ${ }^{14}$ (figura 8); menos de 24 horas después de mi visita al Khuta mafwe. Un joven mafwe de veintiocho años, soltero y de formación secundaria nacido en Katima Mulilo, KD (empleamos unas iniciales falsas por respeto al anonimato del interlocutor), cuyo padre permanece en la cárcel desde su encarcelamiento en 1999 por su implicación en el intento de secesión, me habla apasionadamente de su defensa del UDP, el United Democratic Party, tras desenterrar una jugosa zanahoria plantada por sus propias manos y crecida sin más fertilizante que la bosta de vaca (figura 9), y me explica que él nunca podrá estar en paz mientras su padre continúe en la cárcel. Cómo habría de poder estarlo, cuenta. Plantea la situación como si fuera del todo punto injusto por parte del Estado namibio el hecho de mantener a su padre en la cárcel, si bien está probado que esta persona apoyó activamente el intento de secesión armada, acaso empuñando con sus propias manos algunas de las armas proporcionadas por la UNITA angoleña.

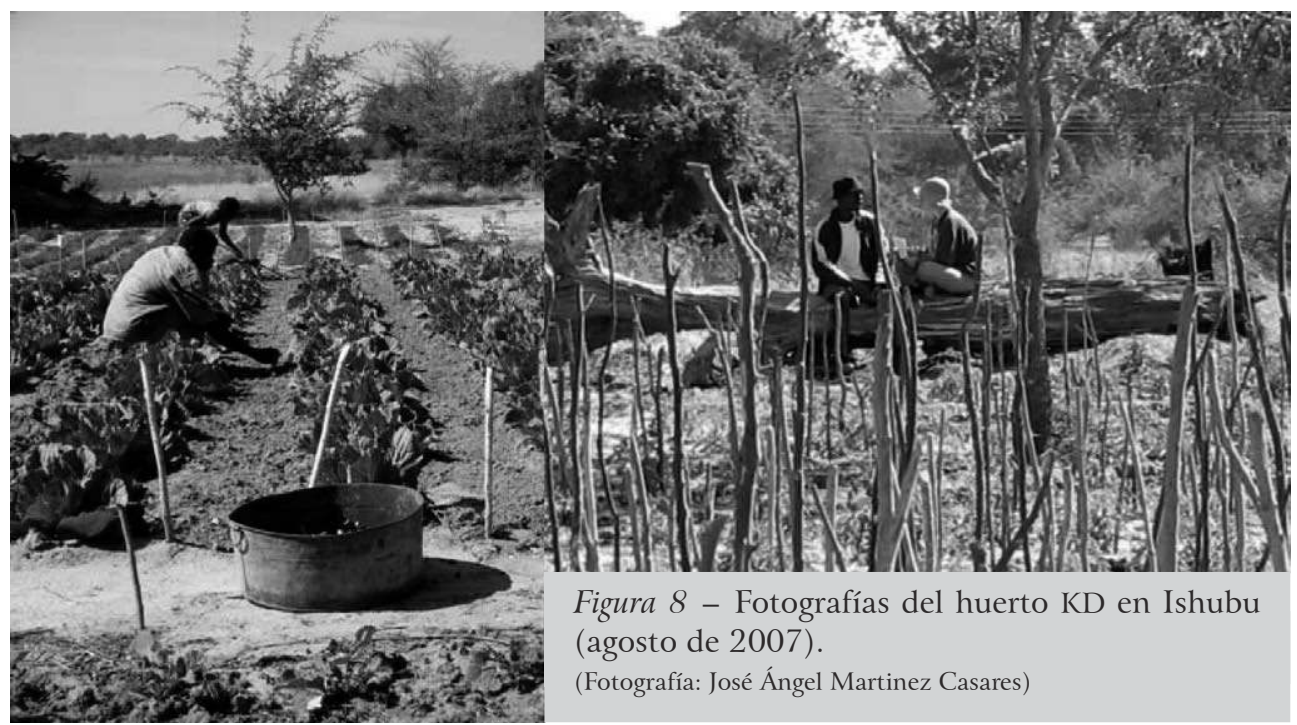

14 Katima Rural y Katima Urban son dos comarcas - constituencies - diferentes, con administraciones separadas. El total de comarcas en la región capriviana es de seis. 


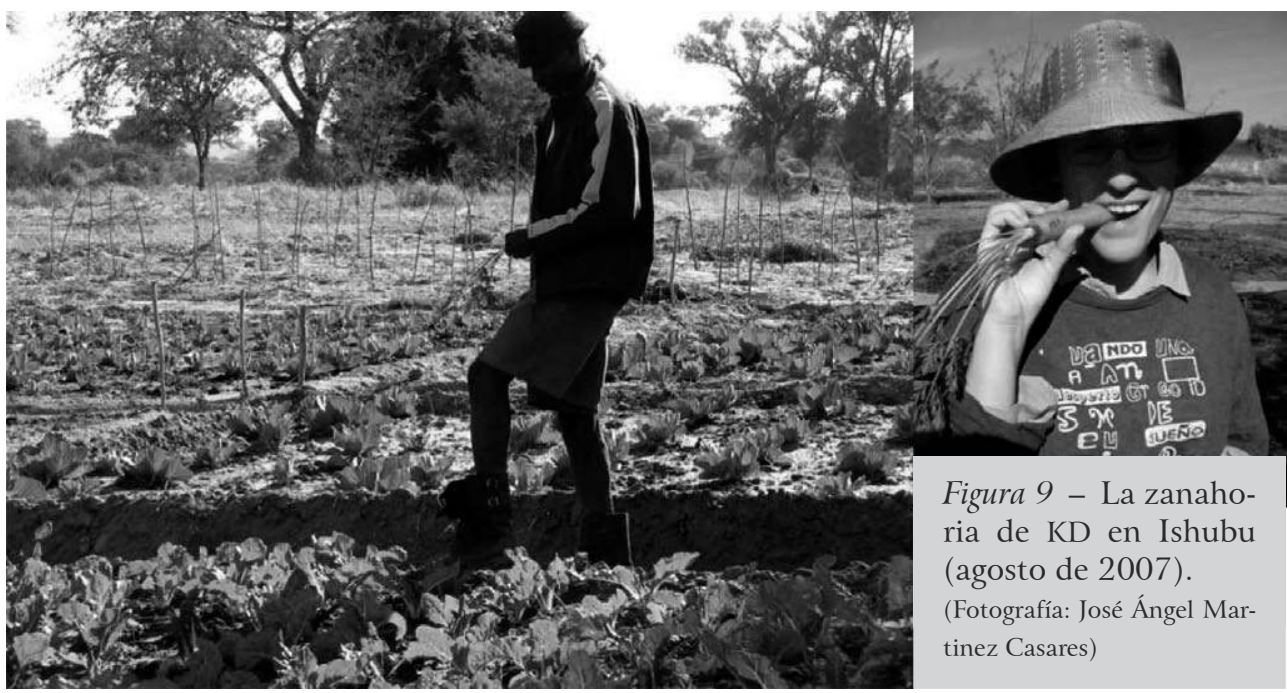

KD representa a la perfección las inquietudes de los ciudadanos namibios descontentos con su "namibianeidad", viviendo, al fin, una nacionalidad impuesta (escuadrada tras la colonia); KD es un notorio exponente del "caprivianismo" deseoso de no ser namibio, es decir, del grupo de personas en Caprivi que dota a su gentilicio regional (Caprivi-an) de la aspiración de llegar a ser nacional. Que clama, pues, por la independencia de Caprivi frente a un Estado y un gobierno, los de Namibia, con los que se sienten francamente infra representados, olvidados, maltratados y reducidos.

Desde la independencia, cuenta KD, Katima ha ido "hacia abajo"; "éramos la primera región", explica, en cuanto a desarrollo, y ahora somos la penúltima; estos datos son técnicamente ciertos, de hecho. ¿Por qué? ¿Qué ha sucedido? ¿En dónde residen las culpas y responsabilidades de inquietudes como las de $\mathrm{KD}$ ?

¿De qué estamos hablando, al fin? He comentado más arriba que la exigua decoración en la sala de la audiencia real de Khuta mafwe, en Chinchimani, se completaba con varios pósters de SWAPO, propaganda de SWAPO y fotografías del actual gobierno. SWAPO (South West African People Organization) es la mayor fuerza política en Namibia, y el partido en el gobierno desde la independencia en 1989. El gran partido de oposición a SWAPO, DTA (Democratic Turnhalle Alliance) constituye en realidad una alianza de diversos partidos, uno de los cuáles, hasta su escisión alrededor de mediados de los noventa, era UDP (United Democratic Party) - ése que KD, nuestro "mafwe contestatario", defiende con ardor.

¿Dónde ésta ahora UDP? ¿Es legítimo que un mafwe, bajo la autoridad del Khuta mafwe por ende, no apoye a SWAPO, al gobierno, si lo hace su jefe?

El partido UDP se halla formalmente prohibido por el gobierno, en estos momentos. Fue la agrupación política que, tras la mencionada escisión, lideró 
Albert Mishake Muyongo para luchar por la independencia de Caprivi. El UDP puede considerarse el "brazo político" del movimiento militar que el 2 de agosto de 1999 llevó a cabo el intento de secesión armada que comenté más arriba. Muyongo, sin embargo, se hallaba ya para entonces (desde el 1998, en que el UDP es ilegalizado) en el exilio, en régimen de asilo político en Copenhague, Dinamarca, junto al también exiliado antiguo rey mafwe, Boniface Mamili.

Un rey en el exilio... por fin llegamos al meollo de la cuestión: el actual rey mafwe, comprensiblemente miembro de SWAPO tras la represión que el gobierno imprimió en la zona después aquel ataque de agosto (es decir, en cierta medida, este nuevo rey, si bien miembro de la casa real y el correspondiente por línea sucesoria en caso de muerte del anterior, había de pertenecer a SWAPO para tornar de nuevo la situación aceptable para con el statu quo nacional), este rey, repito, el que yo conocí... ¿̇seguiría siéndolo en caso de que el anterior, aún vivo, regresara del exilio?

Existen, hoy por hoy, dos reyes mafwe, a pesar de que uno esté en el exilio, en tanto que aún hay algunas personas que le reconocen cierta legitimidad al de Copenhague.

Me contaban hace poco (de nuevo, respeto el anonimato de la fuente) que Mishake Muyongo está convencido, aún hoy, de que la auténtica y legítima corte mafwe se halla ahora en el piso de un suburbio de Copenhague, y que se esfuerza por guardar allí las mismas normas de protocolo, con cualquier visitante que desee conocer a su rey, que yo hube de observar en el Khuta de Chinchimani en el corazón de África.

Creo que ahora, poco a poco, empezamos a entender algo del miedo del Khuta, algo de sus recelos y reluctancias causados por la "división" que hay en el "lado mafwe" y de esas "mentiras" que alguien pudiera contarme por ahí.

Tratemos ahora del mencionado libro de Maria Fisch, tan cacareado en Namibia y condenado por tantos. Apenas un par de meses después de agosto de 1999, Maria Fisch, médica alemana afincada en Namibia desde hace décadas y que ha realizado mucho trabajo de campo en Caprivi, publica un brevísimo librito (véase bibliografía) que trata de explicar las raíces y los motivos de la secesión. En aquel momento resultó muy delicado, incluso algo temerario, el hecho de publicar aquel libro, estando tan recientes los trágicos sucesos por los que murieron personas, tantas fueron encarceladas y otras tantas fueron al exilio. Se hirieron demasiadas sensibilidades, al parecer, en un instante aún prematuro; especialmente a los favorables a SWAPO y denigrantes de la secesión se los llevaron los demonios, ya que la posición de Fisch es claramente justificativa de la idea secesionista y los motivos históricos que la asisten.

El año pasado, durante mi primera estancia de campo, consideré de gran interés realizar una entrevista persona a Maria Fisch. Tuve la suerte de conocer en Windhoek a un amigo personal de ella que me proporcionó su dirección postal (vive en Swakopmund, en la costa) y su teléfono, aunque me advirtió 
que ya estaba muy mayor y delicada. Decidí escribirle una respetuosa carta donde le exponía mis intereses, además de mostrarle mi admiración por su extenso trabajo en la región, y le hablaba de la posibilidad de desplazarme a Swakopmund cuando fuera un buen momento para ella. No me respondió en modo alguno; esperé y, finalmente, opté por el teléfono.

Lo cierto es que lo que puedo contar de aquella breve pero interesantísima conversación telefónica con la insigne Maria Fisch posee, tal vez, más información en lo que no dijo, en su silencio, que en lo que explícitamente sí se dignó a decir.

En primer lugar confirmó, con bastante antipatía, que sí había recibido mi carta y que si no yo no había tenido noticias de ella era porque no le interesaba la entrevista. Así tal cual. Después me insistió mucho en que buscara otro tema de investigación, porque el de la secesión era muy delicado y ella lo había pasado muy mal, encontrando malas caras en ambos "bandos", siempre acusada de favoritismo al contrario, incluso hostigada por el gobierno y los Khutas, etc., etc. Que buscara otro tema y me dejara de complicaciones.

La conversación fue breve y, debo decir, por cierto, bastante desagradable. Poco después comenté la experiencia con un amigo y notable investigador capriviano, y su juicio y consejo en torno a lo que yo iba a indagar fue completamente diferente: me animó a ello y consideró que, al fin, las razones de Fisch para desanimar a un investigador (la verdad sea dicha, actitud poco intelectualmente osada y honesta, por cierto), probablemente fueran de índole más personal que profesional.

Pero volvamos a $\mathrm{KD}$, nuestro cultivador mafwe contestatario. Existe una página web creada por Muyongo y sus seguidores, www.caprivifreedom.com, donde los "rebeldes" (así los llaman) cuentan su versión de la historia y los hechos, y defienden, en fin, la posibilidad de condición de nación (y por ende de Estado) para Caprivi. Conoces esa página... pregunta KD, esa página, eso es lo que yo creo, ahí lo puedes encontrar, todo eso es verdad.

Le pregunto por el rey, por su rey mafwe, el que yo conocí. Me responde con reluctancia, dudoso; "ese rey... sí... lo respeto... lo temo... (nótese cómo la expresión del temor recuerda en buena medida a esa noción de temor a dios en tiempos pasados, esa idea del respeto a través del miedo tan defendida en el Antiguo Testamento de la Biblia; el rey, en Caprivi, no deja de poseer ciertos grados de divinidad) pero... no está haciendo lo que debería... está asociado a SWAPO..." Entonces le pregunto por el rey en el exilio, el anterior; muy enfático y entusiasmado, el joven KD asevera que aquel sí era un buen rey, un rey bravo, valiente, que hizo tanto por su tierra. Resulta evidente que, si bien KD no tiene más remedio, por respeto a la tradición, que aceptar a su nuevo rey, no se siente muy contento con su línea y, decididamente, no se halla precisamente representado por él.

Recapitulemos. La cuestión de por qué traigo a colación, en este colofón acaso un poco extraño, al joven y emprendedor KD, es porque él solito explica 
a la perfección, más que cualquier referencia histórica posible, aquel miedo del Khuta tan incómodo para mí y que motivaba su censura. El Khuta mafwe no descansará mientras en su propio seno cuente con tales disensiones, en tanto que su gran antagonista, el Khuta masubia, goza de una (nunca perfecta, pero sí sólida) unidad feliz en su incuestionable apoyo a SWAPO ${ }^{15}$ y en la unicidad de su lengua, sisubia, y de su gente.

\subsection{Los "peros" de los "mafive puros"}

Otra de las "divisiones" que podía temer el Khuta era la misma interna dentro del seno mafwe. El Khuta de los mayuni y el Khuta de los mayeyi fueron en el pasado parte de la alianza mafwe; es decir, carecían de un rey independiente. La "secesión" mayeyi en 1993 y la mayuni en el 2000, ambas auspiciadas por la Ley de Autoridades Tradicionales, no fueron precisamente motivo de alegría para el Khuta mafwe, que considera ilegítimas las casas reales de sus antiguos súbditos (como dato curioso, el actual rey mayeyi trabajaba como guardaespaldas del rey mafwe).

En concreto, el movimiento de separación de los mayuni comenzó en 2000, pero no fue hasta 2004 cuando finalmente el Khuta mayuni obtiene la "independencia", es decir, el derecho a constituirse como institución de autoridad tradicional independiente, con un consejo propio (es decir, jefe, Ngambela, Natamoyo y consejo de indunas repartidos por el área de tierra comunal asignada), pagado por el gobierno namibio (de modo que, a todos los efectos, podemos considerar, como en los casos anteriores, que los jefes tradicionales devienen en cierta medida funcionarios de Estado, si bien parte de un "cuerpo de funcionarios" bastante particular). La cuestión del reparto de la tierra, como resulta obvio, no es en absoluto baladí, sino que más bien constituye uno de los conflictos fundamentales: los mafwe no sólo "pierden" gente bajo su jurisdicción, con esta escisión, sino que pierden tierra (ya que lo que otorga sentido a un consejo tradicional es tener personas y área territorial bajo su cobijo; añádase a esto que los mayuni no luchan sólo actualmente por el nombre, sino también porque se aumenten las tierras bajo su jurisdicción, apelando a motivos de pertenencia histórica) (entrevista personal con el Khuta mayuni el 24 de agosto de 2007 en el Mashi Khuta, su emplazamiento real).

Por otro lado, resulta de igual interés que los mayuni reclamen en estos momentos su condición que "puros mafwe" o "verdaderos mafwe" porque, como aducen, son los que realmente hablan lengua mafwe propiamente dicha.

15 Este incuestionable apoyo por parte del Khuta subia no significa que todo subia sea de SWAPO; existen, bien al contrario, notables fisuras y disensiones. Realicé, entre otras, una entrevista (en Katima Mulilo, 24 de julio de 2007) con uno de los miembros más destacados del DTA en Caprivi de la actualidad (dentro de la alianza del DTA, un miembro del grupo llamado NUP, National Union Party); esta persona es subia, y confesó que a veces las relaciones con su Khuta no resultan fáciles precisamente por su no adscripción a SWAPO. La pluralidad, siempre, está servida en Caprivi... 
Como he mencionado, los mafwe tradicionales constituyen una alianza étnica más que una etnia y, dentro de esta alianza, el subgrupo étnico al que pertenece el actual Khuta habla la lengua llamada mbalangwe, no la propiamente llamada mafwe; sin embargo reclaman, pretendiendo la cuestión lingüística, en este caso, superflua, que lo importante del asunto es la unidad proverbial y secular de todos los mafwe bajo el ala del Litunga mafwe (unidad que, por otro lado, no se invoca con respecto de otros grupos etnolingüísticos de Caprivi con los que, bien al contrario, se profesa una manifiesta rivalidad) ("Mashi (mafwe) traditional authority" 2007). La discusión está servida.

Hoy por hoy, pues, el Khuta mafwe no mantiene buenas relaciones con los otros tres Khutas de la región (figura 10), ${ }^{16}$ mientras que éstos sí lo hacen entre sí: conversan y parlamentan con regularidad y se visitan oficialmente en sus respectivas fiestas de honor. El Khuta mafwe, en cambio, no hace nada de esto; vive, pues, en el aislamiento de su miedo, del imperativo constante de demostrar su lealtad a SWAPO, en la paranoia de poder ser visto como favorable a los "rebeldes" y en la sensación de que han perdido a parte de la gente que, por tradición, les pertenecía.

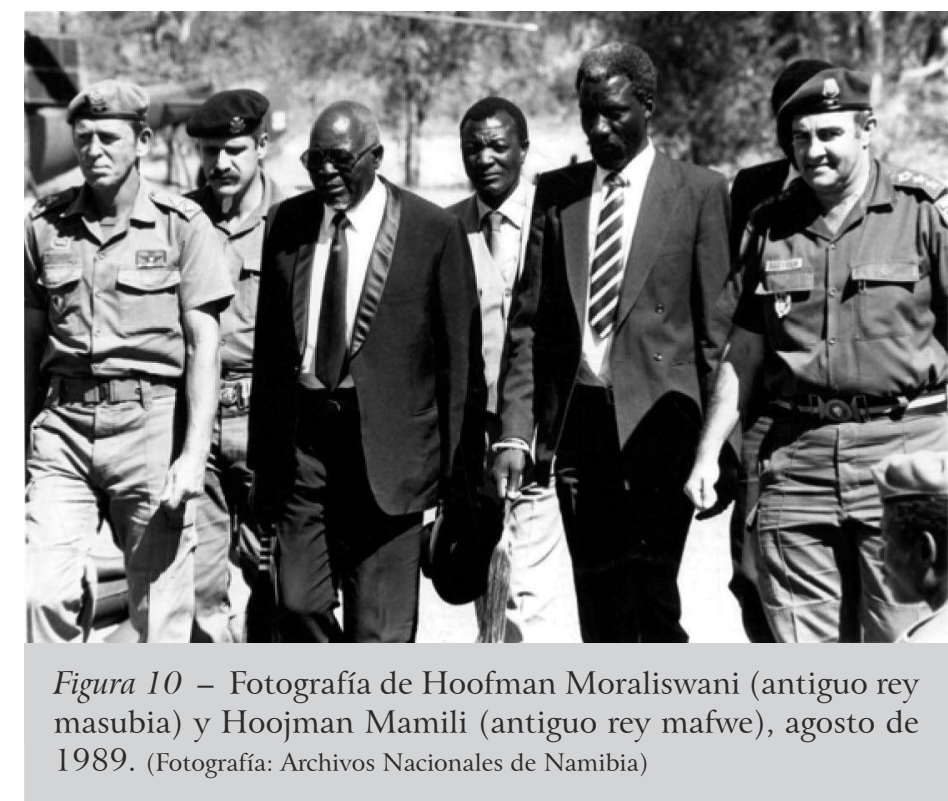

16 Como puede observarse en esta interesante imagen histórica, estas relaciones "reales" no han sido siempre, en efecto, tan desafortunadas: en 1989 aún caminaban ambos reyes, mano a mano, enfrentándose al común enemigo encarnado en el bóer blanco. 


\section{REFLEXIÓN FINAL}

"Era un mundo civilizado desde hacía siglos, con miles
de sendas y caminos." (Ondaatje 1995: 187)

La relevancia de estas observaciones para el tema que nos ocupa es notable. Llevamos a cabo las descripciones densas de ciertas vivencias y participaciones no como interés folclórico de recolección de "datos curiosos", sino motivados por una inquietud, una intención inicial de comprobar en primera persona, y en la realidad, planteamientos e hipótesis de los que encontramos en los libros, y de los que nuestra propia imaginación puede sugerirnos una buena parte.

Así, de un lado, existía el interés genuino de conocer cómo sería la experiencia, antropológica, humana, de un encuentro de la autora en tanto que investigadora, mujer, occidental, con un consejo tradicional africano y, en especial, con un rey de una etnia local. Sin embargo persistía también, de otro lado, la importancia de poder contrastar los detalles, a veces incluso los implícitos, de esta experiencia con las turbulentas y complejas vivencias de lo político, las diversas lealtades, las adscripciones plurales e híbridas que, en esta región, asumen los actores sociales a caballo entre el lenguaje de la tribu y el lenguaje de la nación - metafóricamente hablando. Poder observar "en carne viva" la inquietud de un Khuta "venido a menos", su necesidad de demostrar la lealtad al partido dominante o su disensión en cuanto a los caminos independientes que han adoptado segmentos étnicos anteriormente pertenecientes a "su alianza", como he venido relatando, supone en gran medida contrastar en la realidad la teoría conocida sobre el tribalismo político o la ingente cantidad de bibliografía escrita hasta la fecha en torno a la dialéctica de la etnicidad y la nacionalidad en África, esos dos grandes irreductibles, entre las dos aguas de la reinvención y el conflicto.

El dilatado proceso de una investigación doctoral (dilatado ya no solo en el tiempo objetivo sino, especialmente, en el tiempo subjetivo e interno del investigador) supone mucho de transformación y maduración, a través de grandes pantanos de soledad y (auto) cuestionamiento. En el caso específico de una investigación que implique trabajo de campo antropológico, pienso que la experiencia se ve doblemente enriquecida por el elemento humano y personal que siempre conlleva. Aprendemos no sólo a buscar y discriminar información en bibliotecas - físicas y electrónicas -, sino también a viajar al otro lado del mundo si hace falta, a encontrarnos con "los otros" en otras lenguas (acaso para constatar que somos "otros") y dejarnos en ello el corazón, sin perder el alma, sin perder la subjetividad. Aprendemos a hablar a través de las distancias y diferencias, a salvar obstáculos burocráticos y psicológicos, a dormir en lugares diversos escuchando voces lejanas o el rugido extraño de los hipopótamos, sin perder la ecuanimidad, la capacidad de análisis. 
El investigador o investigadora que se deja, finalmente, los sueños en el camino; que cree que ha llegado a ser capaz de la objetividad y la completitud sin vetas, sin conflictos, ha perdido con ello lo que probablemente sea la grandeza fundamental de una investigación. Las preguntas, el camino. El sendero.

\section{Eri nsuwa, khepwanye}

(proverbio elomowe; aquello que ha provocado el sonido de las hojas, no ha podido ser encontrado $)^{17}$

Katima Mulilo-Granada, julio-octubre de 2007

\section{BIBLIOGRAFÍA}

AMNISTÍA INTERNACIONAL, 2006, "The Caprivi treason trial: justice delayed is justice denied”. Informe de Amnistía Internacional [online]. Disponible en: www.amnestyinternational.org (acceso en 08-08-2006).

CAPLAN, Gerald L., 1971, The Elites of Barotseland, 1878-1969. A Political History of Zambia's Western Province. Londres, C. Hurst \& Co. Publishers.

DUMONT, René, 1963, El África Negra Ha Empezado Mal. Barcelona, Seix Barral.

HINZ, Manfred O., 2005, "African indigenous law: a living but complex reality", en Customary Law, I. Windhoek, Universidad de Namibia, Facultad de Derecho, Human Rights \& Documentation Centre (inédito).

— 2002, "Two societies in one - institutions and social reality of traditional and general law and order", en Volker Winterfeldt, Tom Fox, y Pempelani Mufune, 2002, Namibia: Society and Sociology. Windhoek, University of Namibia Press, Faculty of Humanities and Social Sciences, pp. 197-226.

HOBSBAWM, Eric, y Terence RANGER, 1996 [1983], The Invention of Tradition. Cambridge, Cambridge University Press.

FANON, Frantz, 1964, Por la Revolución Africana (Escritos Políticos). México, Colección Popular Tiempo Presente.

FISCH, Maria, 1999a, The Secessionist Movement in the Caprivi: a Historical Perspective. Windhoek, Namibian Scientific Society.

FISCH, Maria, 1999b, The Caprivi Strip During the German Colonial Period: from 1980 to 1914 [with a chapter on the boundary dispute up to the present]. Windhoek, Out of Africa Publishers.

17 Citado por Albert Farré Ventura al comienzo de su tesis doctoral "Estat modern i llinatges locals a Moçambic. Els dicursos de la legitimitat en u na història d'imatges distorsionades i expectatives incomplertes", 2004, Universidad de Barcelona. 
FOSSE, Leif John, 1996, Negotiating the Nation in Local Terms. Ethnicity and Nationalism in Eastern Caprivi, Namibia. Oslo, Departamento y Museo de Antropología, Universidad de Oslo (tesis doctoral).

KANGUMU, Bennett, 2006, "Andrew Matjila and traditional festivals in the Caprivi: the other side of the coin", New Era, 6 de octubre de 2006.

MAMDANI, Mahmood, 1996, Citizen and Subject. Contemporary Africa and the Legacy of Late Colonialism. Londres, Pricentown University Press.

"Mashi (mafwe) traditional authority", 2007. Khuta Mayuni (Mashi). Documento inédito.

NAmiBIAn GOVERnMent, 1999, Ten Years of Freedom, Peace and Prosperity. The Namibian Constitution, $10^{\text {th }}$ Independence Aniversary. Windhoek, Namprint.

ONDAATJE, Michael, 1995, El Paciente Inglés. Barcelona, Plaza \& Janés.

WINTERFELD, Volker, 2002, "Traditionalism - social reality of a myth”, en Volker Winterfeldt, Tom Fox, y Pempelani Mufune, 2002, Namibia: Society and Sociology. Windhoek, University of Namibia Press, Faculty of Humanities and Social Sciences, pp. 227-238.

YA NANGOLOH, Phil, 2006, “The Caprivi case and absolute prohibition of torture". Windhoek, Namibian Society of Human Rights.

Ethnographic narration of a royal meeting: a visit to the Mafwe Khuta, Caprivi region, Namibian State - Ester Massó Guijarro - Investigadora FPU, Departamento de Filosofía II, Universidad de Granada (España) • ester@ugr.es

This article presents a classic ethnographic narrative through thick description. The anthropological events of a visit to a Khuta - traditional authority - mafwe in the Caprivian region of Namibia (bordering Zambia, Zimbabwe, Botswana and Angola), are analysed, through the inevitable subjectivity of fieldwork (considering it as richness, in opposite at an impossible neutrality). Ethnographical narrative is used as a pretext to illuminate some of the crucial comprehension keys on the current relations between autochthonous traditional authorities and the Namibian government, in the wake of the secession revolt on August 1999, which involved the political exile of the former mafwe chief - splinter supporter - opposite the current one - government follower. Through ethnographical subjectivity, it is intended a human accurate complex approach to a thick social reality, full in its turn of various subjectivities, historical contingencies and inescapable vital arbitrariness.

KEYWORDS: ethnographic narration, Caprivi (Namibia), thick description, mafwe traditional authority, armed secession. 